Aus dem Anat.-Biol. Institut der Universität Berlin

(Direktor: Geh. Rat Prof. Dr. O. Hertwig).

\title{
Zur Kenntnis der Epidermoidalgeschwülste von Kaltblütern.
}

Histologische Veränderungen des Integuments und der Mundschleimhaut beim Stint (Osmerus eperlanus L.).

Von

Theodor Breslauer.

Hierzu Tafel XVI-XVIII und 6 Textfiguren.

\section{Inhalt:}

Seito

1. Einleitung . . . . . . . . . . . . . . . 201

2. Bisherige Veröffentlichungen über Fischgeschwülste . . . . . . 202

$$
\text { Allgemeines. }
$$

3. Material . . . . . . . . . . . . . . . . . . 208

4. Der Sitz der Stintneubildungen und ihre Verteilung am Fischkörper 209

5. Die Häufigkeit der Stintneubildungen. . . . . . . . . . 212

6. Die äussere Form der Stintneubildungen . . . . . . . . 213

7. Das Verhältnis der einzelnen Neubildungsformen zueinander . . . 215

$$
\text { Spezieller Teil. }
$$

8. Die flossenständigen Neubildungen . . . . . . . . 217

Zusammenfassung . . . . . . . . . . . . . . . 226

9. Die kopfständigen Neubildungen . . . . . . . . . . . . 227

A. Organoide Formen . . . . . . . . . . . . . . . . . . 128

B. Primitive Formen . . . . . . . . . . . . . . . 246

Zusammenfassung . . . . . . . . . . . . 252

10. Schluss . . . . . . . . . . . . . . . . . $20 \overline{0}$

$$
\text { A n h a } \mathrm{ng} \text {. }
$$

Literatur . . . . . . . . . . . . . . . . . . . . . . 259

Erklärung der Abbildungen 1-31 auf Taf. XVI-XVIII . . . . . . . 261

Erklärung der Abkürzungen im Text und auf den Tafeln . . . . . , 263

Tabelle über die Verteilung der Neubildungen auf der Körperoberfläche der Stinte 


\section{Einleitung.}

Bei seinen Untersuchungen über die Mikrosporidie Gl u gea hertwigii an Stinten aus Rügen fiel Herrn Privatdozenten Dr.W e i s s e $n$ b e rg, Assistent am hiesigen Anatomisch-Biologischen Institut, in Sommer 1913 am Kopf eines konservierten Stintes ein Tumor auf, welcher sich durch seine dunklere Färbung und bedeutendere Grösse von den schneeweissen Mikrosporidiencysten unterschied. Probeschnitte ergaben, dass es sich um eine Epithelgeschwulst handele. Als sich daraufhin im Herbst noch einige weitere Stinte mit solchen Kopfgeschwülsten aus Rügen beschaffen liessen und es sich herausstellte, dass diese dort wăhrend des Winters in geradezu endemischer Weise aufzutreten pflegen, übergab mir Herr Geheimrat $\mathrm{Hertwig}$ das Material zur genaueren Untersuchung.

Gleich an dieser Stelle gestatte ich mir, meinem hochverehrten Lehrer, Herrn Geheimrat Hertwig, meinen Dank auszusprechen für die Wahl dieses Themas, sowie für seine vielfachen Anregungen im Laufe der Untersuchung. Ganz besonders fühle ich mich anch Herrn Privatdozenten Dr. We is senberg zum Dank verptlichtet für seine rege Anteilnahme am Fortschreiten dieser Arbeit.

Da über die histologiscben Verănderungen des Integuments und der Nundschleimhaut der Stinte, soweit ich mich aus der mir zugänglichen Literatur überzeugen konnte, noch keine Mitteilungen vorliegen, so möchte ich die Arbeit mit einer kurzen orientierenden Zusammenfassung einleiten, die uns einen Begriff von den histologischen Veränderungen gibt und davon, was insbesondere an ihnen interessiert.

Es stellen die Veränderungen - äusserlich betrachtet bald mehr oder minder höckerige Gebilde von unregelmässiger Gestalt vor, die häufig in Form von selbständig wachsenden Körperanhängen auf dem Integument und der Mundschleimhaut der Stinte multipel aufzutreten pflegen. Es handelt sich hierbei nicht um Einzelfälle unter den Stinten, die hier und da einmal beobachtet werden. Im Gegenteil, die Zahl der so betroffenen Fische ist eine auffällig hohe, denn sie beträgt bis zu $20 \%$ eines Fanges. Die Art des Auftretens selbst gewinnt an Bedeutung einmal dadurch, dass sie eine endemis che zu sein scheint, dann aber auch deshalb, weil sie zu gewissen Fragen Veran- 
lassung gibt, die bisher noch wenig wissenschaftliche Bearbeitung gefunden haben. Es weisen nämlich die fraglichen Integumentund Mundschleimhautgebilde nicht jenen histologischen Bau auf, der für durch parasitäre Infektion verursachte Erkrankungen - Granulome - typisch ist. An diese sollte man entsprechend der endemischen Verbreitungsart der histologischen Veränderungen zunächst denken. Ihre mikroskopische Untersuchung zeigt vielmehr, dass sie - wie bereits eingangs erwähnt - im wesentlichen Neubildungen des Epithels, Epitheliome, darstellen. Bemerkenswert ist dabei, dass sich auch das Bindegewebe des Coriums in den meisten Fällen so stark am Aufbau der Neubildungen beteiligt, dass diese einen fibroepithelialen Charakter annehmen.

Schliesslich soll noch hervorgehoben werden, dass die Verbreitung der histologischen Veränderungen auf das Integument und die Mundschleimbaut beschrănkt bleibt. Ihre Verteilung auf diese Körperbezirke ist aber keine ungesetzmässige, sondern gewisse Gegenden werden vorzugsweise befallen. Hierzu gehören in erster Linie die freien Mundränder und die Flossen, ferner die Kanäle der Seitenlinien und die Nasengruben, gelegentlich einmal auch die Kiemen.

\section{Bisherige Veröffentlichungen über Fisch- geschwülste.}

Neben einer Reihe von Eigentümlichkeiten, die ich in der Literatur noch nicht veröffentlicht fand, wurden im Laufe der Untersuchung der Stintneubildungen auch eine Anzahl Erscheinungen festgestellt, wie sie in mehr oder minder ähnlicher Weise auch bei gewissen bereits bekannten Neubildungsformen anderer Fischarten vorkommen. Ehe ich daher auf die oben genannten Befunde ausführlicher eingehe und sie begründe, möchte ich zunăchst über frühere Veröffentlichungen von Fischgeschwülsten berichten, soweit sie zu den bei den Stinten gefundenen histologischen Veränderungen Beziehungen aufweisen.

Es existieren bereits eine ganze Anzahl von Publikationen über Fischgeschwülste und zusammenfassende Übersichten. Solche, wie sie z. B. von Margarete Plehn 1910 gegeben worden sind, lehren, dass Fischneubildungen von fast allen Gewebsarten ihren Ausgang nehmen können. 
Besonders zahlreich sind die Berichte über Fischgeschwülste der Bindesubstanz. Man kennt Fibrome (Fiebiger 1909, Ple hn 1906), - Osteome (Plehn 1906, Schröders 1907), - Fibrosarkome (Plehn 1906, Schröders 1907), - Osteosarkome (Murray 1908, Provazeck 1904). Ferner sind bekannt je ein Fibromyxom (Schröders 1907), - Lipofibrom (Plebn 1906), - Osteochondrom (Fiebiger 1909).

Diesen gutartigen Neubildungen steht eine Reihe von Sarkomen gegenüber von mehr oder minder bösartigem Charakter: Spindelzellensarkome (Schröders 1907, Bashford-Murray 1907), - Polymorphzellensarkome (Ple hn 1906, Bonnet 1883), - Sarkome (Plehn 1909), ferner je ein Rundzellensarkom (Schröders 1907), - Riesenzellensarkom (Bugnion 1875), Myxosarkom (Ple hn 1906). Letztere beschreibt auch eine Narbengeschwulst, ein Keloid (1906) und eine Organgeschwulst, ein Odontom (1912).

Viel geringer ist die Anzahl der uns bekannten Fischneubildungen, welche dem Muskelgewebe angehören. Es sind dies zwei Hyome (Plehn 1906) und ein Rhabdomyom (Fiebiger 1909).

Von Endotheliomen finden wir sogar nur eins veröffentlicht (Schröders 1907), ferner je ein Endothelioma pigmentosum (Schröders 1907) und ein Hamangioendotheliom (Plehn 1906).

Neubildungen, die vom Nervengewebe der Fisclie ihren Ausgang nehmen, sind bisher merkwürdigerweise überhaupt noch nicht beschrieben worden.

Sehr häufig finden wir wiederum Berichte über Epitheliome (Plebn 1906, Fiebiger 1909, Keysselitz 1908, Schröders 1907) und ebenso über Karzinome (Plehn 1906, 1909, M urray 1908, Bashford-Murray 1904, Dauwe und Pennemann). Ferner existieren Mitteilungen über gut- und bösartige Neubildungen der dem Epithel sehr nahe stehenden Drüsengewebe wie Adenome (Schröders 1907, Pick und Poll 1903, Bashford-Murray 1904) und ein Adenokarzinom (Pick 1905).

Die letztgenannten Neubildungen, welche von Epithel- und Drüsenzellen ausgehen; sind es, welche im Hinblick auf die vorliegenden histologischen Veränderungen der Stinthaut ein besonderes Interesse beanspruchen. Am bekanntesten unter ihnen ist das Thyreoideakarzinom der Salmoniden. Dieser Schilddrüsen- 
krebs stellt eine bösartige Erkrankung dar, welche oft unter Hinraffung vieler Tausende von Exemplaren fast alle Arten von Zuchtsalmoniden, wie Lachs und Forelle, epidemisch befallen kann. Auch erkrankte Wildfische wurden beobachtet. Mit der Histopathologie dieses Thyreoideakarzinoms hat sich Pick in einer Monografie ausführlich befasst, desgleichen MI. Plehn, die eine Anzabl aus Deutschland herrührende Fälle untersucht hat. Allerdings sind dies nur sehr wenig Exemplare im Verhältnis zu den grossen Massen, die die Epidemieen in Südafrika und Australien, vor allem aber in den Vereinigten Staaten, den Forschern in die Hände liefern. Nach M. Plehn (1912), deren Zusammenfassung über das bisher vom Schilddrüsenkrebs der Salmoniden Bekannte das neueste mir erreichbare Werk darstellt, entsteht jener aus einer Vorkrankheit, dem gutartigen Kropf. Beide sind den entsprechenden Krankheitsformen beim Warmblüter vollkommen vergleichbar. Die Tatsache, dass das bösartige Thyreoideakarzinom aus gutartigen Formen hervorgeht, sei mit Rücksicht auf gewisse Beobachtungen am Stint besonders hervorgehoben. Zunächst handelt es sich nur um Drüsenepithelwucherungen in Form kleiner Knoten. Doch sehr häufig erfahren: sie eine gewaltige Vermebrung. Sie dringen dann nicht selten bis zur Kehlgegend vor und in die Mundböhle hinein. Auf dem Wege ihrer schrankenlosen Ausbreitung zerstören sie Muskeln und Knochen und greifen dabei auch die Gefässwănde an. Letzteres ist wohl, wie Plehn besonders betont, das gefahrlichste Moment für den Träger, um so mehr, als es sich um die wichtigsten Gefässe, Kiemengefässe und Aorta, handelt. Auffăllig ist die eminent hobe Erkrankungsziffer. In einem extremen Fall waren es ca. $70 \%$ der Bewohner eines Teiches, die befallen waren. Bei dieser Zahlenangabe muss man freilich im Auge behalten, dass es sich hier um Zuchtfische handelt, die sich innerhalb einer geschlossenen Anlage befinden.

Eine andere Epithelwucherung, die für die Fischzüchter Bedeutung besitzt, ist die unter dem Namen Karpfenpocken bekannte Erkrankung der Cypriniden. Mit dem Schilddrüsenkrebs der Salmoniden stimmen die Karpfenpocken in dem häufigen Auftreten überein. Charakteristisch für sie ist ibre multiple Verbreitung auf dem Integument, sowie dessen alleinige Beteiligung an ihrer Bildung. Da sich ganz ähnliche Verhåltnisse 
bei den Stintgeschwülsten finden, so sei es erlaubt, etwas ausführlicher auf die Karpfenpocken einzugehen.

Was wir von der Karpfenpocke wissen, danken wir in erster Linie M. Plehn. In einem "Hautepitheliome bei Cypriniden" betitelten Kapitel ihrer 1906 veröffentlichten Arbeit „Über Geschwü]ste bei Kaltblütern" schildert sie die Krankheit folgendermaßen: „Die Pockenkrankheit der Karpfen besteht im Auftreten von Hautwucherungen, die in extremen Fällen mehr als die Hälfte des Körpers bedecken können. In den Anfangsstadien bemerkt man stellenweise kleine weissliche Flecken, die ein wenig durchscheinend sind, wie Milchglas, und die zunächst nur unbedeutend prominieren. Im Verlauf einiger Wochen sieht man sie stark an Ausdehnung zunehmen und auch in die Höhe wachsen. Sie können $4-5 \mathrm{~mm}$ hoch werden. Die Obertiache ist meist glatt, doch kann sie auch gerunzelt erscheinen. - Die Konsistenz der Wucherungen wechselt, sie können sich fast knorpelhart anfühlen, sind aber manchmal auch weicher." Die mikroskopische Untersuchung zeigt, dass "die Pockenflecken nichts anderes sind als Epithelwucherungen, die fast immer das Bild von fast durchaus gutartigen Wucherungen geben. Bei jungen Knoten sieht man tadellos regelmässige Epithelzellen, die in keiner Weise ein abnormes, überstürztes Wachstum erkennen lassen. - Wenn das Gebilde dicker wird, verändert sich der Anblick, die Zellen bekommen eine wechselnde Gestalt. Sie können je nach den Druckrichtungen geradezu spindlig werden, ähnlich Bindegewebszellen, sie können auch in kugliger Schichtung zusammenliegen, so dass man von einem Kankroid sprechen könnte, wenn eine Spur von Verhornung da wäre, die der Fischhaut fehlt. Oft kommt es vor, dass die Ernährung des stetig wachsenden Gebildes nicht recht Schritt halten kann; dieses nekrotisiert dann stellenweise. Es entstehen im Innern Herde von zerfallenen Zellen, in denen man die verschiedensten Arten von Kerndegenerationen antrifft. Der Zerfall kann bis zur Oberflache fortschreiten, so dass ein breiiger Detritus austritt." Sehr bemerkenswert ist die Tatsache, dass die Karpfenpocken häufig den Zustand einer primitiven Epithelwucherung aufgeben und den Charakter einer mehr oder minder komplizierteren - organoiden - Epithelgeschwulst annehmen.

Von den bisher in der Literatur veröffentlichten Epithel- 
geschwülsten der Fischhaut sind für unser Thema noch von besonderem Interesse die von $\mathrm{K}$ eysselitz bearbeiteten Lippenepitheliome der Barben. Auch beim Stint finden sich ja die Wucherungen sehr häufig an den freien Mundrändern lokalisiert. Es muss daher auf die Befunde von Keysselitz etwas genauer eingegangen werden. In seiner 1908 erschienenen Arbeit gibt er eine ausführliche Schilderung der Kopfgeschwülste. die ich im Auszuge hier folgen lasse: „Auf den wulstigen Lippen der Moselbarben (Barbus thuv. Cuv.) kann man öfters ein Epithelioma beobachten. Dasselbe kann an allen Stellen der Lippe sitzen, selten greift es auf die Haut des Oberkiefers über. Es erreicht Hirsekorn- bis Erbsengrösse. Hăufig findet man nur einen einzigen, seltener mehrere, drei bis vier Epitheliome, die räumlich voneinander entfernt sind oder sich berühren. Dieselben besitzen an der Basis im Querschnitt eine rundliche bis ovale Gestalt und stellen entweder flache Buckel mit leicht höckeriger Oberfläche oder kegelförmige Gebilde dar. Ihre Farbe gleicht der Lippe (gelblichweiss). Mitunter sind sie an der Obertläche leicht oder stärker erodiert. Nach Angaben der Fischer treten sie häufiger im Frühjahr auf und verschwinden im Sommer. - Mitosen fehlen. Relativ häufig sieht man einzelne oder mehrere dicht beieinander liegende Zellen in hyaliner Degeneration begriffen. Derartig veränderte Zellen zerfallen später. In den oberflächlichen Schichten beobachtet man auch öfters Zellen, die eine andere, meist hyalin degenerierte und im Zerfall begriffene Zelle umschliessen. Die Papillen sind langgestreckt und laufen meist spitz aus. Sie reichen bis tief in das Epithelioma hinein. In der Nahe der Papillen liegen die Zellen dicht gedrängt beieinander und weisen eine längliche Gestalt auf." Wie später noch genauer ausgeführt werden wird, hat Keysselitz in den Kernen der Epitheliomzellen eigentümliche Einschlüsse beobachtet. Er deutet sie als Parasiten (Chlamydozoen) und erblickt in ihnen die Erreger der Krankheit.

Auch sonst sind lippenstandige Neubildungen bei Fischen bekannt. So berichtet Fiebiger von einem Epitheliom an der Lippe bei einer Tinca vulgaris und von einem Fibrom am Mundwinkel eines Gadus virens (Kohler).

Wie bereits erwähnt, sind die Stintneubildungen nicht immer kopfstăndig, sondern treten oft multipel an verschiedenen Körper- 
stellen, insbesondere auch an den Flossen auf. Ein ähnliches Verbalten ist von Fiebiger 1909 für drei andere Fische beschrieben worden. An je einem Exemplar von Anabas scandens und Cyprinus carpio fanden sich nămlich multiple Hautepitheliome, die u. a. auch an den Flossen sassen. Von Interesse ist es, dass einer der flossenständigen Epitheliomknoten des Karpfens destruktive Tendenz zeigte. Eine weitere flossenständige Neubildung erwähnt Fiebiger (1909) bei einem Gadus virens (Kohler). Es handelt sich allerdings hier um ein Fibrom. Epithelwucherungen, wie sie die Karpfenpocken darstellen, sind nicht nur auf den Flossen der Karpfen beobachtet worden. Plehn (1906) berichtet auch von pockenartigen Epithelwucherungen auf den Flossen eines Nerflings (Leuciscus idus Heck) und einer Rotfeder (Leuciscus erythrophthalmus L:).

Der Umstand, dass die Neubildungen des Stintes gelegentlich auch an den Kiemen auftreten, veranlasst mich, auch über die wichtigsten bisher beschriebenen Kiemenepithelwucherungen einen kurzen C̈berblick zu geben. Am bekanntesten ist eine Kiemenerkrankung der Bachforelle, die Hofer (1898 und 1906) ausführlich beschrieben hat. Das Epithel der Kiemenblaittchen beginnt hier lebhaft $\mathrm{zu}$ wuchern und verwandelt die zarten, respiratorischen Fältchen in dicke Kolben um. Ausser bei Bachforellen sind diese histologischẻn Veränderungen des Kiemenepithels auch bei Regenbogenforellen und Bachsaiblingen gesehen worden (Plehn 1909). Meist befällt die Krankbeit zahlreiche Exemplare. In noch stärkerem Maße werden die Kiemen durch eine Epithelwucherung verunstaltet, wie sie nach einer Mitteilung Plehns (1909) Mazarelli von den Agoni (Alosa finta Cuv.) und Clupea finta aus dem Luganer See beschrieben hat. In den von Mazarelli beobachteten Fälen macht die Erkrankung nicht mit der Umwandlung der Kiemenblättchen in keulenförmige Anschwellungen Halt, sondern das gewucherte Epithel einer Anzahl benachbarter Kiemenblättchen verschmilzt miteinander. Die Krankheit tritt epidemieartig auf.

Das gehäufte Auftreten dieser Kiemenepitbelwucherungen hat Marg. Plehn beim Studium der Forellenerkrankung veranlasst, sorgfaltig darauf zu achten, ob Mikroorganismen als Erreger nachweisbar wären. Es war jedoch nur möglich, eigentümliche Zelleinschlüsse aufzufinden, die nicht selbst Parasiten darstellen 
können, immerhin aber eine gewisse Ähnlichkeit mit Einschlusskörperchen aufweisen, wie sie von verschiedenen Infektionskrankheiten, wie Variola und Lyssa, als Reaktionsprodukte der Zellen auf das Eindringen des Virus beschrieben worden sind. Da ich auch unter den Stintneubildungen in einigen Fallen ähnliche Zelleinschlüsse beobachtet habe, so sei der von Plehn (1909) erhobene Befund hier noch im Auszuge angeführt. „In dem Plasmaleib einer ziemlichen Anzahl von Zellen findet man als Einschluss einen grossen, rundlichen Klumpen, meist hat er Kugelform, selten sind mehrere kleine Klümpchen vorhanden. Besonders an Präparaten, die in einfachster Weise mit Hämatoxylin und van Gieson gefärbt sind, treten die Einschlüsse ungemein scharf und klar hervor; sie haben meist im Gegensatz zu dem tief blau violetten Chromatin des Kernes einen helleren rotvioletten Ton angenommen, in vielen Zellen erscheinen sie gelblich. Die Zellen mit Einschlüssen finden sich oft regionenweise gehïuft; in weiten Strecken können sie auch ganz fehlen. Sie sitzen meist in der Umgebung der Gewebslïcken oder am Rande der Geschwulst."

\section{Allgemeines.}

\section{Material.}

Was das Material anbetrifft, so standen - mir zu Beginn der Untersuchungen nur drei - tot konservierte - Stinte zur Verfügung, die ausschliesslich mundständige Neubildungen aufwiesen. Nach und nach gelang es aber, ihre Anzahl auf $37 \mathrm{zu}$ erhöhen, wovon 14 im lebenden Zustande eintrafen. Die lebend konservierten Exemplare lieferten ein vorzügliches Intersuchungsmaterial. Alle Fische stammen aus dem Jasmunder Bodden. Die Beschaffung des Materials erfolgte durch Herrn Fischer Ed. Wothke in Lietzow auf Rügen, dem ich auch an dieser Stelle meinen besten Dank sage.

Konserviert wurde in Formol, Pikrinsublimateisessig, Zenkerscher Flüssigkeit, Flemmingscher Flüssigkeit und Alkoholeisessig (Abs. Alc. 95 T., Eisessig 5 T.). Hinsichtlich der bei manchen Präparaten (Kopf, Flossen, Kiemen) notwendigen Entkalkung lieferte die Konservierung mit Pikrinsublimateisessig die besten Resultate, wahrend das Flemminggemisch eine sehr lange Entkalkungsdauer erforderlich machte. Entkalkt wurde, soweit dies 
nicht bei einigen Präparaten die Pikrinsublimateisessiglösung schon vollständig besorgt hatte, mit 5 proz. Salpetersäure und zwar je nach Bedarf $1-8$ Tage lang. Vor der Wässerung kamen die Präparate auf $12-24$ Stunden in eine 5 proz. Alaunlösung.

Die Schnittdicke betrug $2-5 \mu$ bei Tumorteilstücken, 5 bis $20 \mu$ bei Schnitten durch ganze Köpfe.

Zum Färben bewährten sich folgende Zusammenstellungen: Hamatoxylin Böhmer, Hämalaun, Heidenhain - Eosin, Lichtgrün, van Gieson, nach Eisessigalkoholkonservierung auch Biondi und nach solcher mit Flemmingscher Flüssigkeit Safranin - Lichtgrün.

Ehe ich nunmebr auf die năhere Beschreibung der Stintneubildungen im einzelnen eingehe, möchte ich ihren Gesamtcharakter, soweit er sich makroskopisch dem Beschauer darbietet, noch etwas genauer als in der Einleitung schildern. Hierbei ist. der Sitz der Tumoren, ihre Verteilung am Fischkörper, ihre Hüufigkeit im Auftreten und ihre aussere Form zu berücksichtigen.

\section{Der Sitz der Stintneubildungen und ihre Verteilung am Fischkörper.}

Wenn wir die Neubildungen auf ibren Sitz hin untersuchen, so können wir in jedem Falle konstatieren, dass sie dem Integument oder der Schleimhaut der Mundhöhle aufliegen. Die Annahme, dass diese Bezirke ausschliesslich beteiligt sind, wurde schon zu Beginn der Untersuchungen sehr wahrscheinlich gemacht durch negative Befunde bei der Sektion der inneren Organe. Sie fand aber vollends ihre Bestätigung durch die mikroskopische Untersuchung, selbst in solchen Fällen, wo die ungeheure Ausdehnung der Tumoren eine Herkunft derselben von Skelett-; Muskel- und sogar ganzen Organteilen vermuten liess, zum allermindesten aber eine Beteiligung dieser Organsysteme an der Geschwulstbildung.

Die Haut und die Schleimhaut werden nicht in gleicher Weise befallen. Denn während Hautpartien bisweilen isoliert Träger von Neubildungen sind, stehen die erkrankten Schleimhautbezirke fast stets mit solchen der Haut in Verbindung.

Was die Verteilung der histologischen Veränderungen am Fischkörper anbetrifft, so zeigt es sich, dass der viscerale Kopfteil der Lieblingssitz der Tumoren ist. Von den 37 mir zur 
Beobachtung gelangten Exemplaren sind bis auf 2 Fälle alle an dieser Region mit Geschwülsten behaftet. Dagegen bleibt der übrige Kopfteil im allgemeinen verschont. Eine Ausnahme bilden nur solche Falle, wo etwa die Nase, die Kanäle der Seitenlinien und zum Teil auch das Epithel der Konjunktivalfalte in grösserem Umfange mit in die Neubildung hineinbezogen sind, oder wo der Tumor ganz exorbitante Dimensionell angenommen hat, so dass er sich von vorn bis weit hinter die Augen erstreckt.

Am visceralen Kopfteil sind wiederum die freien Mundränder in ganz auffälliger Weise befallen. Bei den 35 Exemplaren, wo der viscerale Kopfteil Träger von Neubildungen ist, sind die Lippen $32 \mathrm{mal}$, die anderen Regionen dagegen nur vereinzelt betroffen.

Die Verteilung der Neubildungen an den Ober- und Unterlippen ist insofern sehr bemerkenswert, weil sie in einem sichtlichen Einklange steht mit einer durch viele Befunde erklarten Tatsache, wonach sich die Stintneubildungen besonders auf exponierten Gegenden des Integuments entwickeln. So zeigen z. B. die freien Mundrander - entsprechend ibrer bei der Vorwärtsbewegung des Fisches besonders gefährdeten Lage - gemeinhin eine auffällig höhere Erkrankungsziffer als alle anderen Körpergegenden. Ferner lehrt die histologische Untersuchung gerade der lippenständigen Neubildungen, dass diese am meisten vom normalen Hautorganisationstyp abweichen. Dieses Verhalten entspricht aber deutlich einem chronisch rerlaufenden Krankheitsprozess, der durch eine Anhäufung von Reizen gerade an dieser exponierten Stelle - nämlich an den Lippen - bedingt wird. Man dürfte somit wohl erwarten, dass die Mitte der Lippen als der exponierteste Teil der letzteren am öftesten betroffen ist, ganz besonders aber die Mitte des freien Unterkieferrandes, welcher beim normalen Stint den Oberkiefer bedeutend überragt. Merkwürdigerweise entspricht nun die Verteilung der Neubildungen an den freien Mundrandern durchaus nicht jenen Erwartungen. Zunächst zeigt es sich nämlich, dass Oberlippe und Unterlippe fast gleich häufig befallen sind. Ferner erkennt man, dass ihre Mitte äusserst selten erkrankt ist. Nur dann, wenn sich der Tumor über den ganzen oder einen grösseren Teil der freien Mundränder erstreckt, geben diese auch in der Witte eine Unterlage für die Gescbwulst ab. Dabei liegt die höchste Er- 
hebung des Tumors stets ausserhalb der Mediangegend. Selbst. in den Fällen, wo man eine ganze Anzahl lippenständiger Neubildungen an einem Exemplar beobachten kann, ist sehr oft kein Tumor in der Mitte der Lippen vorhanden.

Ausser den Seitenteilen der Mrundränder sind häufig auch die Nundwinkel Träger von Neubildungen. Das Integument am freien hinteren Maxillarende ist dann vorwiegend beteiligt. Da sich die 'Tumoren oft auch eine ganze Strecke an den freien Mundrändern entlang fortsetzen und nur bei genauerer Beobachtung eine oder mehrere. Grenzfurchen an eine getrennte Entstehungsweise denken lassen, so konnte ich in der beigefügten Tabelle über die Verteilung und den Sitz der Neubildungen die Zahl der Geschwülste nicht genau angeben. In den Fallen, wo z. B. in der Tabelle Mundwinkel und Lippe als Sitz angegeben sind, handelt es sich somit manchmal auch um durch eine Brücke verbundene Neubildungen. Dieselben scheinen unabbängig voneinander entstanden und bei fortschreitender Entwicklung wegen Raummangels miteinander verschmolzen zu sein.

In einer Anzahl von Fällen erstrecken sich die Neubildungen bis tief in die Mundhöble hinein. Sie gehen dann aber fast durchweg von Geschwülsten an den Lippen aus und nicht von Tumoren an den Mundwinkeln. Haufig findet man auch, dass zwei Tumoren an den treien Mundrändern der Ober- und Unterlippe sich gegenüberstehen. Sie sind dann verschieden gross. und verschieden gestaltet. Die Annahme, zwei gleichzeitig entstandene Neubildungen hätten in diesen Fällen eine ungleich-. mässige Entwicklung erfahren, ist hier recht unwahrscheinlich. Vielmehr liegt der Verdacht, dass die eine Neubildung früher entstanden ist als die andere und die Ursache für diese abgegeben hat, hier so nahe, dass ich schon an dieser Stelle darauf hinweisen möchte.

Nur in zwei Fallen sind Neubildungen am visceralen Kopfteil vorhanden, ohne dass die freien Mundränder befallen sind. In dem einen ist die Haut zwischen den Radii branchiostegi und. ferner der erste rechte Kiemenbogen befallen, in dem anderen. die Haut hinter dem Unterkieferschleimkanal. Merkwürdigerweise ist auch sonst an diesen beiden Fischen keine Neubildung. weiter am ganzen Körper zu entdecken. Dieses fällt um so mehr auf, als die Multiplizitat im Auftreten als Norm anzusprechen. 
ist, derart, dass sie zu den spezifischen Eigentümlichkeiten der Stintneubildungen zählt. Diese multiple Verbreitung geht so weit, dass ein freier Mundrand oder eine Flosse oft eine ganze Anzahl von Neubildungen - bis zu sechs Stück und darüber aufweist. Dieses Verhalten liess sich aber in der Tabelle wegen mehrfacher Grenzfälle statistisch nicht zum Ausdruck bringen.

Neben dem visceralen Kopfabschnitt erweisen sich die Flossen als ganz besonders prädisponiert. In zwei Fallen sind sogar samtliche Flossen Träger von Neubildungen, mit Ausnabme der Fettllosse. Letztere ist auch in keinem anderen Falle an der Bildung der Tumoren beteiligt. An der Flosse selbst sind die breiten Flächen vorwiegend befallen, während auf die Flossenkante die Neubildung nur übergreift, sobald sie bereits einen unverhältnismässig grossen Raum auf der Flosse eingenommen hat.

Die histologische Untersuchung lehrte, dass auch in der Nase und in den Kanălen der Seitenlinien die Neubildungen anzutreffen sind. Makroskopisch war aber günstigenfalls nur eine Veränderung am Naseneingang $z u$ bemerken. Im Naseninnern sind hauptsächlich die Nasenfalten ergriffen, dagegen fast gar nicht die Schleimhaut der Nasenblindsäcke. Sowohl bei den Epithelgeschwülsten der Nasen wie den der Seitenlinien war ein Zusammenhang mit der Hauterkrankung dadurch ersichtlich, dass auch die natürlichen Kommunikationswege befallen waren.

\section{Die Häufigkeit der Stintneubildungen.}

Die Häufigkeit des Auftretens der bistologischen Veränderungen unter den Stinten ist sehr bemerkenswert. Denn nach Zahhlungen des Fischers, welcher mir die mit Neubildungen behafteten Stinte einsandte, sollen diese $20 \%$ des jeweiligen Fanges darstellen. Diese Angabe kann natürich bei weitem nicht als so zuverlässig gelten, wie die von Gaylord (Plehn 1912) hinsichtlich der Verteilung der kranken Salmoniden in den Teichen einer geschlossenen Anlage. Eine exakte Feststellung der Erkrankungsziffer wird meiner Ansicht nach auch nicht so leicht einwandsfrei gelingen, schon deshalb nicht, weil wir es bei den Stinten, die für die Neubildungen in Frage kommen, mit in der offenen See frei herumschwimmenden Fischen zu tun haben.

Während nun das Thyreoideakarzinom der Salmoniden und die Pocken der Cypriniden nicht nur bei vielen Arten dieser 
Fische auftreten können, sondern, wie erwähnt, fast auf der ganzen Erde gefunden werden, sind die vorliegenden Neubildungen mir bisher nur von den Stinten aus dem Brackwasser des Jasmunder Boddens bei Rügen bekannt. Auch bei den Süsswasserstinten, welche aus verschiedensten Gegenden in die Berliner Markthallen in kolossalen Mengen hineingebracht werden, habe ich trotz öfteren Nachsuchens keine mit derartigen Neubildungen gefunden. Ich muss daher die Verbreitung der histologischen Veränderungen im Gegensatz zu der epidemischen der Schilddrüsenerkrankung und der Karpfenpocken als eine endemische bezeichnen, bis anderwärts gleichartige Befunde bei Stinten mitgeteilt werden wie die vorliegenden.

\section{Die äussere Form der Stintneubildungen.}

Noch mannigfaltiger als der Sitz und die Verteilung ist die äussere Form der Geschwülste. Von einer stecknadelliopfgrossen kaum bemerkbaren Erhebung bis zu den abenteuerlichsten, die Flosse und ganz besonders den Kopf vollstandig entstellenden Gebilden kann man alle Übergangsformen beobachten. Darum hält es schwer, einen Normaltyp für die äussere Gestait der Neubildungen anzugeben. Sehr leicht lassen sich aber gewisse Merkmale für eine Anzahl von Neubildungen angeben, sobald man solche zusammenfasst, die durch ihre gemeinsame Lage auf der Körperoberfläche ausgezeichnet sind. So finden wir zum Beispiel auf den Flossen keulen- oder spindelförmige, flach ansteigende Verdickungen von weisslich grauer, schwach opaleszierender Farbe. Sie sind für den ungeübten Beobachter schwer wahrnehmbar, da sie fast vollkommen unter der gleichfarbigen, gesunden Umgebung verschwinden. Andere Hossenständige Neubildungen stellen hirsekornförmige Gebilde dar. Sie sind infolge ihrer Trübung und ihrer scharf begrenzten Gestalt trotz ihrer Kleinheit viel leichter erkennbar als die vorigen.

Die Hlach ansteigenden Formen finden wir auch am Kopfe vor, wenn auch weit weniger häufig als an den Flossen. Ebenso wie dort zeigen sie hier das Bild einer lokalen Verdickung, die ohne zirkumskripte Grenze in die Umgebung übergeht. Jedoch erfahren sie am Kopf eine grössere Flächenausdehnung. als an den Flossen, wo, wie später genauer ausgeführt wird, besondere 
Momente die Ausbildung einer Keulen- oder Spindelgestalt begünstigen.

Die Obertläche aller bisher aufgeführten Neubildungen ist eben. Eine Ausnahme machen nur jene Fälle, wo beginnende oder teilweise schon durchgeführte Verschmelzungen einzelner Tumoren $\mathrm{zu}$ Gruppen tiefe Furchen bedingen. Bei den keulenförmigen, flossenständigen Formen, die meistens mit ihrer Längsseite verschmelzen, sind die Furchen zjemlich gerade. Bei den birsekornförmigen, die oft in grösserer Anzahl von verschiedenen Richtungen her aufeinander zugerückt $\mathrm{zu}$ sein scheinen, bildet die Grenzfurche eine gebrochene Linie.

Im Gegensatz zu den eben genannten Neubildungen, die zum Teil infolge ihrer relativen Kleinheit sowie der teilweise nur sehr schwer konstatierbaren Niveauerhebung auch von uns erst spät beobachtet wurden, stehen alle übrigen Formen, welche ausschliesslich kopfstandige sind. Ihre beträchtliche Grösse, ihre oft eigenartige Furbung, vor allem aber ihre ausgeprägte Prominenz selbst in jugendlichen Stadien macht sie schon auf den ersten Blick zu sehr auffälligen Gebilden. Die jüngsten Neubildungen sind etwa stecknadelkopfgross. Nicht selten sieht man solche von Bohnengrösse. Sie haben sich dann auf ibrer Ausgangsflache mebr der Lange als der Breite nach entwickelt. Dieses Verhalten betrifft vorwiegend viele lippenständige Gebilde. Gleich die ersten Exemplare, welche aus Rügen gesandt wurden, zeichneten sich durch måchtige Geschwülste an der Kopfgegend aus. Das vordere Ende ist hier oft unförmig verdickt. Furchen ziehen regellos über die Oberfläche hinweg. Eine besonders ausgeprägte sitzt mitunter ganz vorn. Sie stellt den Rest der Mundspalte dar. Ihre auffallende Verlagerung ist nur eins der vielen schon ausserlich erkennbaren Symptome für die später noch zu erwăhnenden Skelettdeformitäten, die die Entwicklung der Geschwulst bei vielen Stinten bewirkt. Oft sieht es aus, als ob ein unförmliches Gebilde aus der Mundöffnung hervorquillt. Manchmal wieder ist es ein Tumor mit starken seitlichen Ausladungen, der den $\mathrm{Mu}$ ndrändern aufsitzt, diese aber vollständig verdeckt.

Die Farbe der Neubildungen ist weisslich- bis bläulichgrau. Sie markiert sich um so intensiver, als der Kopf nach den Mundrändern zu stark pigmentiert ist. Es kommt dies am besten an 
den auf Taf. XVI in Fig. 4-6 abgebildeten Präparaten zum Ausdruck, die mit Formalin konserviert sind.

Eine Eigentümlichkeit all der Neubildungen am Kopfe ist es, dass sie von einer gewissen Grösse an ihrer Unterlage mehr oder minder gestielt aufsitzen können. Makroskopisch ist dies mitunter gar nicht wahrzunehmen und wird erst oft bei der histologischen Untersuchung bekannt. Das rührt daher, dass selbst bei einigermaßen langgestielten Formen die Masse der Neubildung viel schneller wächst als der Stiel und zwar nach allen Richtungen, so dass der Tumor der benachbarten Umgebung eng angepresst wird und ihr direkt aufliegt. Dies ist auch der Grund, weshalb besonders grosse Formen, die makroskopisch betrachtet durchaus den Eindruck einer einheitlichen Yeubildung erwecken, bei der mikroskopischen Untersuchung auf senkrecht zur Haut geführten Schnitten sich als zusammengesetzt offenbaren. Abb. 10 auf Taf. XVII zeigt ein derartiges Verhalten. Auch unter den flossenständigen Neubildungen - allerdings nur unter den hirsekornförmigen - gibt es kurzgestielte Formen. Hier lässt sich die Stielbildung leichter konstatieren als am Kopf, ganz besonders bei den isoliert stehenden Neubildungen.

Eine besondere Erwahnung verdienen schliesslich die an der Oberfliche blumenkohlartig zerklüfteten Tumorformen, welche ich nur an den Lippen beobachten konnte. Am lebenden Tier sieht man hier, wie bei jeder Atembewegung langausgezogene Fortsätze der Geschwulst der Strömung des Wassers folgend hin und her Hottieren. Dass dieser beständig ausgeübte Zug hier von entwicklungsmechanischem Einfluss auf die polypösen Fortsătze ist, beweist ihre Längsachseneinstellung in der $\mathrm{Be}$ wegungsrichtung.

Hinsichtlich ihrer Konsistenz verhalten sich die Neubildungen teilweise ăhnlich, wie es Plehn für die Karpfenpocken beschrieben hat. Manchmal geben die Tumoren dem Drucke etwas mehr nach als die betreffende Hautstelle im normalen Zustande. Eine gewisse Elastizität ist dabei zu bemerken. Meistens fühlen sie sich jedoch sehr derb an, beinahe knorpelhart.

7. Das Verhältnis der einzelnen Neubildungsformen zueinander.

$\mathrm{Zu}$ den mannigfachen äusseren Verschiedenbeiten kommt noch ein buntes histologisches Bild. Es entsteht nun die Frage, Archiv f. mikr. Anat. Bd. 87. Abt. I. 
ob und wie diese mannigfaltigsten Formen miteinander verknüpft sind.

Zweifellos sind alle Neubildungen im Grunde einheitlich. Dafür spricht die ausschliessliche Abkunft aller Tumoren vom Integument und der Mundschleimhaut, die Anwesenheit stets derselben Organisationskomponenten - Epithel und Bindegewebe und das vorzugsweise Auftreten der Neubildungen an exponierten Körpergegenden.

Die Unterschiede der einzelnen Iormen in Gestalt und Struktur entsprechen teilweise verschiedenen Altersstadien. So liegen die jungen Neubildungen breitbasig der Unterlage auf. Mit zunehmendem Alter bildet sich ein Stiel aus, der die Neubildung mit ihrem Ausgangsort verbindet. Von den die Neubildungen zusammensetzenden Gewebselementen überwiegt in den jungen Formen das Epithel, in den älteren das Bindegewebe. Schliesslich lassen die jungen Neubildungsformen einen primitive n Bau erkennen, die alteren dagegen einen komplizierteren, einen - organoiden.

Die wichtigsten Unterschiede innerhalb der einzelnen Tumoren erklären sich aber daraus, dass diese sich auf verschiedenen Körpergegenden verschieden entwickeln. An den Flossen finden wir z. B. bei den primitiven Formen selten eine Beteiligung des Coriums, am Kopf dagegen fast stets. Bei den Neubildungen auf den Flossen handelt es sich auf alteren Stadien ausschliesslich um cystenartige Gebilde, am Kopf dagegen in der Regel nur um solche von papillomatösem Bau.

Für die Beschreibung erscheint es somit am zweckmaßigsten, die Lokalisation in den Vordergrund $\mathrm{zu}$ stellen und von diesem Gesichtspunkt aus - einerseits bei den Flossen, andererseits beim Kopf - darzulegen, wie die einzelnen 'Tumoren wohl entwicklungsgeschichtlich verknüpft sind. Hierbei darf die Grösse der Neubildung - als Maßstab für die Altersbeurteilung - nur bei Tumoren von gleichem histologischem Bau Berücksichtigung finden. In allen anderen Fallen dürften wir nicht fehlgehen, wenn wir entsprechend dem von der normalen Haut abweichenden Organisationstyp auf das Alter der einzelnen Formen schliessen. Zur Anwendung eines solchen Verfahrens halte ich mich wohl berechtigt in Anlehnung an entsprechende, von Plehn bei den Cyprinidenpocken und den daraus sich entwickelnden Neubildungen 
gewonnene Ergebnisse. Obgleich die ebengenannte zur Bestimmung des Altersstadiums gewählte Methøde zu Ergebnissen führen muss, die der Wahrscheinlichkeit am nächsten kommen, entspringt sie immerhin einer blossen Schätzung - allerdings unter Berücksichtigung aller dafür in Betracht kommenden Befunde. Ich bin mir darum wohl bewusst, dass ihr dauernder wissenschaftlicher Wert nur durch einen experimentellen Nachweis erhärtet werden kann, welcher mit grossem Zeitaufwand verknüpft und mit eingehenden biologischen Studien verbunden sein würde.

Das gut- oder bösartige Verhalten der einzelnen Neubildungen kann ich nicht zum Ausgangspunkt für die Einteilung aufstellen, schon deshalb nicht, weil die Malignität bei den Kaltblütern von anderen Erscheinungen bestimmt wird als bei den Menschen oder Säugern gemeinhin. Es bedarf daher noch einer Klärung dieses Begriffes, ehe er bei den vorliegenden Fischgeschwülsten in erschöpfender Weise zur Anwendung gebracht werden kann. Ich erinnere auch an die zahlreichen Übergange, die schon Plehn bei Kaltblütern vom gutartigen zum bösartigen Typ beobachten konnte, eine Erscheinung, die auch bei Stinten wiederkehrt.

\section{Spezieller Teil.}

\section{Die flossenständigen Neubildungen.}

An den Flossen finden wir die Neubildungen in zwei Hauptformen vor, die sich voneinander ganz erheblich unterscheiden. Die einen bieten den Anblick einer flachen lokalen Verdickung. Die anderen stellen stecknadelkopf- bis hirsekorngrosse Gebilde dar, welche kurz gestielt der Unterlage dicht aufsitzen.

Histologisch betrachtet lassen sie noch auffälligere Unterschiede erkennen. Jene tlachen Formen zeigen eine ganz primitive Organisation, vorwiegend eine Epithelwucherung, die anderen dagegen einen komplizierteren Bau, nämlich den einer perlenartigen Epithelanhäufung, welche von einer bindegewebigen Kapsel umgeben ist. Da sich in der Regel im Innern der zuletzt genannten Tumoren ein Erweichungsherd bildet, so sei als kurze Bezeichnung. für diese Neubildungsform der Ausdruck Cyste gebraucht.

Die erwähnte Verschiedenheit war anfangs durchgehend anzutreffen und liess keine Möglichkeit zu, die beiden Formen miteinander in Beziehung zu bringen. Endlich gelangten einige 
Neubildungen zur Beobachtung, die beide Charaktere vereinigt aufwiesen. Auf Grund eines Vergleiches der histologischen Befunde - besonders im Sinne der vorhin angeführten Erwägungen ergab es sich nunmehr, dass beide so ungleich aussehende Formen nur verschiedene Entwicklungsstadien repräsentieren. Es stellen nümlich die flachen Epithelauflagerungen die jugendlichen Formen dar. Wegen ihrer Ähnlichkeit mit den Cyprinidenpocken will ich sie als "pockenartige Epithelwucherungen" bezeichnen. Die cystenartigen Gebilde dagegen repräsentieren ein weiter vorgeschrittenes Wachstumsstadium, ja sie scheinen bereits den Höhepunkt der ganzen Entwicklung erreicht zu haben.

Was die Häufigkeit des Auftretens der flossenständigen Neubildungen anbelangt, so ist dieselbe nach vielen Richtungen hin sehr bemerkenswert. So sind unter den 37 mit Neubildungen versehenen Stinten 13, die auch Tumoren an den Flossen aufweisen. Bis auf die Fettflosse, welche ich in keinem einzigen Falle behaftet fand, liessen sich an allen anderen Flossen ohne Ausnabme Neubildungen auffinden. Manchmal war nur eine Flosse erkrankt, meistens waren mehrere, in zwei Fallen alle Flossen von der Fettflosse abgesehen - Träger von Neubildungen.

Hinsichtlich der Verteilung der Tumoren auf die einzelnen Flossen ergibt sich folgendes interessantes Bild. Unter meinem Material von insgesamt 37 Fällen sind am häufigsten die Brustflossen befallen, die rechte neun-, die linke siebenmal. Sodanm kommt die Rückenflosse, welche die Neubildungen in acht Fällen aufweist. Weiterhin schliessen sich an die BauchHossen, die rechts in fünf, links in vier Fällen ergriffen sind. Die After- und Schwanzflossen sind beide nur viermal befallen. Trotzdem die relativ kleinen Zahlen eine statistische Verwertung nur in begrenztem Maße zulassen, sei doch auf die auffällige Tatsache hingewiesen, dass die bei der Vorwärtsbewegung des Fisches besonders exponierten Brust- und Rückentlossen öfters befallen sind als die verhältnismässig geschützten übrigen Flossen.

Oft kann man die Neubildungen in multipler Verteilung auf einer Flossentläche beobachten. Dann konfluieren gewöhnlich mehrere von ihnen zu einer Gruppe. Das geschieht natürlich um so häufiger, je mehr sich auf einer Flosse befinden. Es lässt sich dann, wie bereits oben erwähnt, ihre Anzahl nicht immer eindeutig angeben. Ich habe es darum unterlassen, ihr 
multiples Auftreten auf einer Flosse in ziffermässiger Angabe zum Ausdruck zu bringen oder gar statistisch zu verwerten. Es können sowohl junge Formen zu Gruppen zusammentreten wie alte Stadien. Beide zusammen babe ich nie in einer Gruppe vereinigt gesehen, obgleich ich sie öfters is oliert nebeneinander auf einer Flossentläche beobachten konnte. Besonders gern konfluieren die jungen Formen. Das leuchtet ein, wenn man berücksichtigt, dass die Neubildung in diesem Stadium mehr Platz auf der Flossenoberfläche beansprucht als in dem älteren, zystenartigen (vergl. Taf. XVI, Abb. 2, 5, 11).

Im frühen Zustande fallen die pockenartigen Epithelwucherungen am lebenden Tiere nur sehr wenig auf, ganz besonders, wenn sie isoliert auf der Flosse sich befinden. Da die ersten Exemplare, welche von den mit Neubildungen versehenen Stinten zur Untersuchung kamen, nur riesige Geschwülste am Kopf aufwiesen, keine dagegen an den Flossen, wurde ich erst spät auf die flossenständigen Neubildungen aufmerksam. Da diese auch weit weniger imponieren als die am Kopf befindlichen in derselben Grösse, wurde ihnen anfangs nur wenig Achtung geschenkt, bis schliesslich ihr häufiges Auftreten eine Beziehung zu den oft gleichzeitig vorhandenen Kopfgeschwülsten vermuten liess.

Die zystenartigen Formen sind trotz ihrer viel kleineren Gestalt leichter erkennbar als die pockenähnlichen Epithelwucherungen. Immerhin können sie - ebenso wie jene - sehr leicht übersehen werden, besonders, wenn sie isoliert auf der Flosse auftreten. Eine ausführliche Beschreibung des Habitus der tlossenständigen Neubildungen ist darum wohl angebracht.

Die pockenartige Epithelwucherung, die das Jugendstadium der Veubildung repräsentiert, ist von keulen- oder spindelförmiger Gestalt (siehe Taf. XVI, Fig. 2) und zeigt ein durchsichtiges, schwach opaleszierendes Aussehen. Ihre Farbe gleicht der ihrer Umgebung. Sie ist somit weisslichgrau mit einem leichten Stich ins Bläuliche. Im Wasser ist die Epithelverdickung nicht leicht zu erkennen. Hier betrachtet man sie daher am besten von der Seite. Dann kann man wenigstens ihre sanfte Erhebung über das Niveau der Umgebung beobachten. Das flache Ansteigen bewirkt es, dass bei der Betrachtung von oben herab die Erhebung überhaupt nicht wahrnehmbar ist. Sehr deutlich tritt 
dagegen die pockenartige Epithelwucherung zutage, sobald man die Flosse in Formol fixiert. Die Neubildung trübt sich dann auffallend, während die gesunden Partien der Flosse ihre Durchsichtigkeit behalten. So kommt ein zirkumskripter Flecken zustande, der schon makroskopisch deutlich sichtbar ist. Abb. 2, Taf. XVI stellt eine derartige in Formalin fixierte pockenartige Epithelwucherung dar. Abb. 5, Taf. XVI zeigt eine Anzahl solcher Neubildungen $z u$ einer Gruppe vereinigt.

Auf der Flossentläche ist die spindelförmige Neubildung stets so gelagert, dass ihre Längsachse, die den Breitendurchmesser oft um das 25 fache an Ausdehnung übertrifft, in der Richtung der Flossenstrahlen eingestellt ist. Diese typische Langseinstellung der jungen Epithelwucherung steht offenbar in enger Beziehung zu dem Bau und der Funktion der Flosse. Die Orientierung der Langsachse parallel zu den Flossenstrahlen entspricht nämlich der Richtung, in welcher die Flosse der geringsten Kompression ausgesetzt ist. in welcher also eine rmgestörte Ausbreitung der Neubildung stattfinden kann. Seitlich wird der Tumor dagegen durch die ständige Faltung des Integuments beengt, die durch die gegenseitige Annaherung der Flossenstrablen zustande kommt. Die Bewegung der Flossenstrahlen scheint auch der seitlichen Verschmelzung mehrerer Yeubildungen zu einem einheitlichen Tumor entgegenzuarbeiten. Bei der auf Taf. XVI, Fig. 5 abgebildeten linken Brustflosse eines Stints kommt dieses Verhalten darin zum Ausdruck, dass eine Verschmelzung nur am proximalen Ende der Neubildung (V) erfolgt ist, noch nicht dagegen zum distalen Rande zu (d). Distalwärts ist ja der Ausschlag der Bewegung der Flossenstrahlen ein grösserer als proximalwärts.

Die zystenartigen Neubildungen fallen - wie bereits erwähnt - trotz ihrer kleineren Gestalt viel mehr auf als die Hachen Formen. Das ist zunächst deshalb der Fall, weil sie ein gleichmässig trübes Aussehen besitzen, das ihnen auf der durchsichtigen Flosse eine deutliche Begrenzungslinie verleiht. Dazu kommt noch ihre scharfe Prominenz, welche aus der perlenartigen Gestalt der ihrer Unterlage kurz gestielt aufsitzenden Neubildung resultiert. Auch hier kann man das Zusammentreffen mehrerer Geschwülste zu einer Gruppe beobachten, wie Abb. 11, Taf. XVI es zeigt. Es bleiben aber hier die einzelnen Cysten 
im Gegensatz zu den Verschmelzungsknoten der pockenartigen Epithelwucherungen isoliert erhalten.

Histologisch betrachtet, bietet die flossenständige pockenartige Epithelwucherung vorwiegend das Bild einer mächtigen Epithelanhäufung. Die Epidermis besitzt auf den Flossen normalerweise eine Stärke von 5--6 Zellagen und ruht auf einer Unterlage straffen Bindegewebes. Daran inseriert ein lockeres, zellenreiches Bindegewebsnetz, welches von den Flossenstrahlen bezw. einer sie untereinander verbindenden feinen fibrösen Lamelle ausgeht. Trifft ein Querschnitt durch die Flosse eine pockenartige Epithelwucherung, so sieht man, wie das Epithel in sanfter Steigung sich zu einem flachen Wall erhebt, der, wie auf Taf. XVI, Abb. 13 ersichtlich, an der höchsten Stelle die sechsfache Stärke der normalen Epidermis annehmen kann (w. E). Beobachtet man ein mikroskopisches Präparat etwas genauer, so gewahrt man, dass die Epithelverdickung nicht nur durch eine ungewöhnlich zahlreiche Anbäufung von Epithelzellen zustandekommt. Die Zellen haben vielmehr auch an Grösse ganz bedeutend zugenommen. Hingegen zeigt sich die das Epithel tragende straffe Bindegewebslamelle des Coriums fast gar nicht verändert. Die Fibrillenzüge verlaufen wie im normalen Gewebe. Bei ganz genauem Vergleich kann man jedoch auch hier eine wenn auch zunächst nur geringfügig erscheinende - Veränderung konstatieren. Sie betrifft die Lage der Bindegewebszellen. Normalerweise liegen diese nämlich der untersten Schicht der bindegewebigen Grenzlamelle (s. B) an. In der Neubildung dagegen befinden sie sich auch innerhalb der Fibrillenzüge und dringen selbst bis zur untersten Epithelschicht vor. Bei der Bedeutung, die das Bindegewebe als Organisationskomponente in den alteren Formen gewinnt, muss dieser Umstand beachtet werden.

Yon den flossenständigen pockenartigen Epithelwucherungen leiten zu den cystenartigen Gebilden einige - nur in geringer Anzahl vorgefundene - Neubildungen über, die ich darum als Übergangsformen bezeichnen will. Auf Grund einiger Präparate, die hier nicht abgebildet sind, lässt sich der Übergang der jungen pockenartigen Epithelwucherung zur cystenartigen Neubildung folgendermaßen wiedergeben.

Das jüngste Stadium der Epithelverdickung ist, um noch einmal zu rekapitulieren, auf Taf. XVI, Fig. 13 dargestellt. 
Daran schliesst sich ein Bild, wie es in der ersten der schematischen Textfiguren auf S. 222 zum Ausdruck kommt. Es fällt hier auf, wie sich das Corium (s. B) gerade dort verdickt hat, wo die Epithelwucherung (w. E) ihre höcbste Erhebung zeigt. Dies ist meistens in der Mediangegend der Neubildung der Fall. Diese bindegewebige Verdickung (siehe Textfig. 1, s. B), differenziert sich im weiteren Wachstumsverlauf zu einer Bindegewebslamelle (siehe Textfig. 2, $\mathrm{L}^{1}$ ), welche die wuchernde Epithelmasse (w.E) durchsetzt. Nach einiger Zeit gabelt sich die Lamelle (siehe

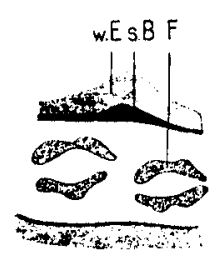

Fig. . 1.

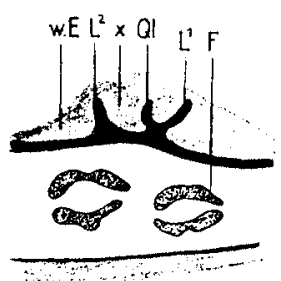

Fig. 4 .

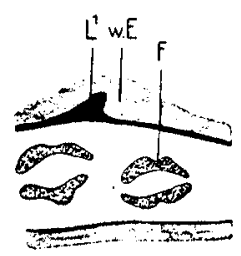

Fig. 2.

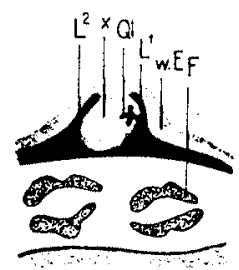

Fig. $\check{\text { y. }}$

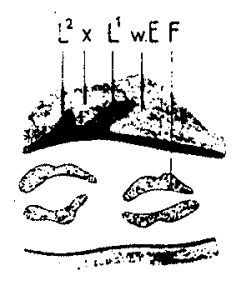

Fig. 3.

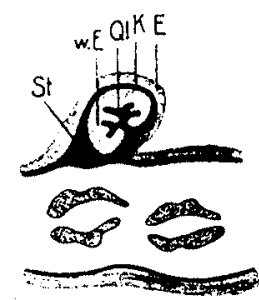

Fig. 6.

Entwicklungsgang einer pockenartigen Epithel w u cherung auf einer Stintilosse (siehe Taf. XVI, Abb. 2 und Abb. 13) zu einer Cyste (siehe Taf. XVIII, Abb. 16) nach Ubergangsformen $s c h$ e $m a t i s c h$ dargestellt.

1. Das Bindegewebe (s. B.) unterhalb der Epithelwucherung (w. E.) verdickt sich.

2. Das Bindegewebe $\left(1, \mathbf{s}\right.$. B.) differenziert sich zu einer Lamelle $\left(L^{1}\right)$.

3. Die Lamelle $\left(2, \mathrm{~L}^{1}\right)$ gabelt sich $\left(\mathrm{L}^{1} \mathrm{~L}^{2}\right)$ und schält aus der Epithelwucherung (w. E.) die mittlere Partie (x) heraus.

4. Die eine Lamelle $\left(L^{1}\right)$ entsendet einen Ausläufer, der die mittlere Epithelpartie (x) durchsetzt.

5. Die beiden Lamellen $\left(\mathrm{L}^{1} \mathrm{~L}^{2}\right)$ nähern sich, der Ausläufer $(\mathrm{Ql})$ verästelt sich. Die seitlichen Epithelstreifen (w. E.) schrumpfen.

6. Die Lamellen $\left(5, \mathrm{~L}^{1} \mathrm{~L}^{2}\right)$ verwachsen zur Kapsel (K). Die Basis (St) der Neubildung wird schmäler. Die bindegewebige Verästelung (Ql) schreitet fort. Die eingeschlossene Epithelmasse (w. E.) degeneriert zentripetal. 
Textfig. 3, $\mathrm{L}^{\mathrm{l}}, \mathrm{L}^{2}$ ). Hierdurch wird die Epithelwucherung (siehe Textfig. 3, w. E), in drei Teile geschieden, wobei dem in der Mitte befindlichen (x) von nun an die Hauptbedeutung zukommt. Indem die Bindegewebslamellen $\left(\mathrm{L}^{1}, \mathrm{~L}^{2}\right)$ dann weiter nach oben wachsen, nähern sie sich allmählich einander und beginnen so, die zentrale Partie der Epithelverdickung (x) mehr und mehr einzukapseln. - Sehr früh sendet die Bindegewebslamelle der einen Seite (siehe Textfig. 4, L'), einen Ausläufer (Q!) in die in der Mitte befindliche Epithelmasse (x) hinein, der sich gleich $z u$ verzweigen beginnt und schliesslich baumförmig verästelt (siehe Textfig. 5, Q1). Sowie sich die Bindegewebslamellen berühren, verwachsen sie und kapseln die eingeschlossene Epithelmasse vollständig ab (siehe Textfig.6, w. E). Mit diesem Stadium ist auch die Umformung der pockenartigen Epithelwucherung zur Cyste erreicht, welche die charakteristische Form der flossenstindigen Neubildungen darstellt.

Um das wesentlichste in der Entwicklung der pockenartigen Epithelwucherung zur Cyste möglichst klar hervortreten zu lassen, habe ich mich nur auf die mittleren Querschnitte beschränkt. Hier ist namlich die Entwicklung stets am weitesten fortgeschritten. Die Enden der spindelförmigen Neubildung durchlaufen die gleichen Stadien erst später.

Auch im Cystenzustande erfăhrt die Geschwulst noch mancherlei Veränderungen, die durch Schrumpfungs- und Degenerationsvorgänge hervorgerufen werden. An der Schrumpfung ist vorwiegend die bindegewebige Kapsel beteiligt (siehe Textfig. 6, $\mathrm{K})$. Auch das über sie hinweglaufende Epithel (E), welches den seitlichen Epithelstreifen (w.E) auf den in Textfig. 3-5 wiedergegebenen Stadien entspricht, hat seine Stärke bedeutend reduziert. So entsteht die hirsekornförmige Gestalt der Neubildung (siehe Taf. XVI, Fig. 11), welche viel kleiner als die jüngere pockenartige Epithelverdickung (siehe Taf.XVI, Fig. 2), ist. Eine andere auffallende Veränderung am Tumor betrifft die Art seiner Verbindung mit der Unterlage. Während er nämlich dieser anfangs breitbasig aufsitzt (siehe Taf. XVI, Fig. 13 und Textfig.1-5), ist er jetzt (siehe Textfig. 6), von der Unterlage abgeschnürt, was zur Ausbildung eines kurzen Stieles geführt hat (St).

Alle die genannten Veränderungen der Neubildung auf dem Cystenstadium sind deutlich aus den in Taf. XVI, Fig. 14, 16 
dargestellten Querschnitten ersichtlich. Auf Fig. 14 ist die Abschnürung der Cyste besonders deutlich ausgeprägt (St), wăhrend dieses Verhalten auf dem in Fig. 16 abgebildeten Fall weniger gut zur Geltung gelangt, da an der Verbindungsstelle die mächtige - aber răumlich beengte - Epithelmasse (w. E) sich zwischen zwei Flossenstrahlen (F) in die Tiefe gesenkt hat. Bei diesen beiden Neubildungen lenkt das Verhalten des Epithels ein erhöhtes Interesse auf sich. Auf dem in Fig. 16 wiedergegebenen Querschnitt durch eine Hossenstandige Cyste ist das bis zur normalen Stärke reduzierte äussere Epithel (E) künstlich abgehoben. Von diesem durch eine dünne bindegewebige Kapsel ( $\mathrm{K}$ ) geschieden, befindet sich im Innern der Neubildung die eingeschlossene Epithelmasse (w. E). Die Kapsel (K) entspricht den Lamellen $\mathrm{L}^{1}, \mathrm{~L}^{2}$, das eingeschlossene Epithel (w. E) dem Teil $\mathrm{x}$ dere Epithelwucherungen auf den älteren im Schema beschriebenen Stadien (siehe Textfig. 3-5, S. 222). Wäbrend nun beim Eintritt der Lamellenverschmelzung (siehe Textfig. 6), das verastelte Bindegewebe (Ql) noch im Zusammenhange mit der Kapsel (K) sich befindet, ist hier auf dem ausgebildeten Cystenstadium eine vollstindige Trennung der bindegewebigen Verästelung eingetreten. wie Serienschnitte durch die ganze Cyste ergeben. Das Bindegewebe ist dabei zu einer eigentümlichen homogenen Masse angequollen (siebe Taf. XVIII, Fig. 29, Ql), ohne seine scharfe Begrenzungskontur oder sein spezifisches färberisches Verhalten eingebüsst $\mathrm{zu}$ haben.

In der Witte des Cysteninnern beobachtet man eine Degeneration der Epithelzellen (Fig. 16, d.E), die wandständig beginnt und zentralwärts fortschreitet. Dieser Degenerationsvorgang wird schon auf früheren Stadien vorbereitet. Solange nämlich das Epithel eine frei nach aussen führende Fläche besitzt (siehe Taf. XVI, Fig. 13 und Textfig. 1-4, S. 222), können die zu oberst befindlichen Epithelschichten ungehindert abgestossen werden. Je mehr aber die Bindegewebslamellen ( $\left.\mathrm{L}^{1}, \mathrm{~L}^{2}\right)$ sich nähern (siehe Textfig. 5), wird der Ausführungsweg. für die abgestossenen Epithelzellen der zentralen Epithelmasse verlegt. Diese Verhaltung begünstigt auch die bindegewebige Verzweigung (Ql) zwischen den Lamellen (siehe Textfig. 5). Im vorliegenden Falle (siehe Taf. XVI, Fig. 16), erfolgt der Degenerationsvorgang nicht in gleichmässiger Weise von der Kapsel (K) nach dem Innern 
zu. Nach aussen hin befindet sich eine wandständige Lage von Epithelzellen (w. E), die einen durchaus funktionstüchtigen Eindruck macht und etwa die 25 fache Stärke der darüber hinweglaufenden normalen Epithelschicht (E) aufweist. Ziemlich plötzlich geht die wandständige Epithelschicht in einen Hohlraum $(\mathrm{H})$ über, welcher mit einer Flüssigkeit und Detritus (d. E) erfüllt ist. Hier kann man die Epitheldegeneration genau verfolgen. Sie geht unter Chromatolyse des Kernes vor sich. Besonders zahlreich sind die degenerierenden Epithelzellen (d. E) zwischen den Lücken der bindegewebigen Verästelung (Q1) eingestreut, die als Ausschnitt aus Fig. 16 in T'af. XVIII, Fig. 29 vergrössert wiedergegeben ist. Während hier (siehe Fig. 16), die einzelnen Epithelschichten teilweise zusammenhängen, sind sie in anderen Fällen in konzentrischen Zonen angeordnet und durch breite Gewebslücken voneinander getrennt. Aber auch da läst sich ein zentripetales Fortschreiten der regressiven Vletamorphose erkennen.

Über das weitere Schicksal der Cysten ist mir nichts bekannt. Das Schrumpfen ibrer Gestalt sowie ihre beginnende Abschnürung von der Unterlage scheint dafür zu sprechen, dass sie sich vollends ablösen.

Eine besondere Stellung nimmt die in Fig. 14, Taf. XVI im Querschnitt abgebildete Cyste ein. Weder eine bindegewebige Verästelung noch Degenerationserscheinungen sind hier zu beobachten. Vielmehr sind alle Epithelzellen durchaus funlitionstüchtig. Darauf weisen die ungemein zahlreichen mitotischen Teilungsvorgünge hin, die man hier beobachten kann. Allerdings findet man sie nur in den wandstandig gelagerten Zellen. Vielleicht ist daher ihr Fehlen im Zentrum als eine Andeutung dafür aufzufassell, dass auch bier in Kürze eine Degeneration einsetzen. würde. Die Mitosen selbst bieten übrigens keine von der Norm abweichenden Befunde. Sehr auffallig ist nun, dass ein Teil der bindegewebigen Kapsel (siehe Abb. 14, K) an einer Stelle stark verdickt ist. Sie nimmt hier den normalen Cutischarakter der Flosse an, indem sie sich unmittelbar unter der darüber liegenden Epidermis (E) zu der typischen straffen Bindegewebslage (s. B) verdichtet. Das gleiche geschieht auch nach innen $\mathrm{zu}$, unmittelbar über der eingeschlossenen Epithelmasse (w. E). Zwischen den straffen Grenzschichten (s. B.) ist dagegen die Bindegewebskapsel (K) zu einem lockeren, zellreichen Gewebe differenziert. Diese 
Erscheinung legt die Frage nahe, ob es sich hier vielleicht um einen Regenerationsvorgang handelt.

Die Epithelzellen im allgemeinen zeigen - abgesehen von den degenerierenden Formen - bei den flossenständigen Nellbildungen nur insofern eine Veränderung gegenüber den normalen Epithelzellen der Flosse, als sie - wie schon vorhin erwähnt bei den pockenartigen Epithelwucherungen auffällig vergrössert sind. Ihre Volumenzunahme - ihr Durchmeser ist um das dreibis vierfache vergrössert - lässt die Zell- und Kernstrulituren besonders deutlich hervortreten. Auffallig ist dabei, dass die Nukleoli durch einen hellen Hof von der übrigen Kernmasse geschieden sind. Auch der Kern selbst wird von einem bellen Hof umgeben, den radiar verlaufende Plasmabrücken durchsetzen.

\section{Zusammenfassung.}

Auf den Flossen trifft man die histologischen Veränderungen in zwei verschiedenen Formen an. Übergänge zwischen beiden lehren aber, dass wir es nur mit $z$ wei verschiedenen Entwicklungsstadien von genetisch einheitlichen Neubildungen zu tun haben.

Die jüngeren Formen bilden weissbläulich abgetönte, Hache, lokale Epithelverdickungen von'spindelförmiger Gestalt, die den Flossenstrahlen parallel der Flosse aufsitzen (Taf. XVI, Abb. 2). Histologisch stellen sie reine Epithelwucherungen nach Art der Karpfenpocken dar (Taf. XVI, Abb. 13). Ihre Zellen sind jedoch stark vergrössert und lassen eigenartige Strukturverhältnisse erkennen. Häufig liegen die Epithelwucherungen zu einer Gruppe vereinigt (Taf. XVI, Abb. 5, Taf. XVI, Abb. 11). Hier - wie auch isoliert - unterstehen sie einem formativen Eintluss der Flossenbewegung. Die Entwicklung zur alteren Form, der Cyste, vollzieht sich, indem das Corium sich zunächst verdickt und dann einige bindegewebige Lamellen in die Epithelmasse hineinsendet, bis ein grosser Teil derselben vollstandig abgekapselt ist (S. 222, Textfig. 1-6). Während nun die Neubildung eine stielförmige Verbindung mit der Unterlage annimmt, reduziert das ausserbalb der Kapsel befindliche Epithel seine Stärke bis zu der des normalen Flossenepithels (Taf. XVI, Abb. 14). Schon vor völliger Abkapselung setzt im Cysteninnern eine unter Chromatolyse des Kernes verlaufende Epitheldegeneration ein, und das ganze Gebilde beginnt zu schrumpfen (Taf. XVI, Abb. 16, Textfig. 6). 
Bemerkenswert dabei ist die Ablösung des in das Cysteninnere hineingewucherten Bindegewebes von der Kapsel, welches eine eigenartige Beschaffenheit annimmt (Taf.XVIII, Abb.29). Gelegentlich beobachtet man in der Kapsel Erscheinungen, die an Regenerationsvorgänge erinnern (Taf. XVI, Abb. 14).

\section{Die kopfständigen Neubildungen.}

Viel variabler in der äusseren Gestalt und in ihrer histologischen Organisation sind die Neubildungen am Kopf. Sie sitzen hier - wie bereits betont - fast ausschliesslich am visceralen Teil und zwar meistens auf der Haut, in wenigen Fallen auch auf der Schleimhaut.

Auf der Haut zeichnen sie sich schon im frühen Stadium durch eine auffallend prominente Gestalt aus, welche mit dem papillomatösen Charakter ihres histologischen Baues zusammenhängt. Am lebenden, im Wasser frei herumschwimmenden Tier sind die kopfständigen Stintneubildungen als balbdurchsichtige Gebilde von milchglasfarbenem Schimmer leicht $\mathrm{zu}$ erkennen, zumal sie auf dem in der Regel pigmentierten Untergrund des Kopfes sich sehr scharf abheben. Hierzu kommt noch ihre auffallige Silhouette, welche die Aufmerksamkeit des Beobachters sofort auf sich lenkt. Sind die Neubildungen am Kopf etwas über erbsengross, so kann derselbe schon derart verunstaltet sein, dass die Orientierung der Mundspalte selbst bei Lupenbetrachtung schwer fällt. Ganz besonders ist dies der Fall, wenn zahlreiche Furchen die Oberfläche der Neubildung durchziehen. Dann dürfen wir in den meisten Fällen annehmen, dass wir einen aus mehreren Einzelgebilden zusammengesetzten Tumor vor uns haben.

Auch hier am Kopf kann man zwei Hauptformen unterscheiden. Die einen weisen einen primitiven Bau auf, ähnlich wie die pockenartigen Epithelwucherungen auf den Flossen, nur mit dem Unterschiede, dass am Kopf das Corium sich meistens ebenfalls verdickt. Diesen Formen gegenüber stehen - sie an Zahl bei weitem übertreffend - organoide Gebilde von vorwiegend papillomatösem Bau. Sie schwanken in ihrer Grösse von einem Stecknadelkopf bis zu einem Taubenei. Genaue Vergleiche ergeben, dass auch am Kopf eine reine Integumentbezw. Epithelverdickung das erste Stadium jeder Neubildung sein 
muss. Doch braucht im Laufe des Wachstums sich nicht immer ein organoider Charakter auszubilden, sondern unter Beibehaltung des primitiven Baues nimmt oft die Integumentverdickung nur an Grösse zu. Indem sie sich hierbei ganz besonders der Fläche nach ausdehnt, kann sie häufig enorme Bezirke umfassen und hierdurch eine bedrohliche Tendenz annehmen. In solch vorgeschrittenen Fällen bemerkt man dann nicht selten, wie das Bindegewebe stellenweise sich anschickt, in das Epithel hineinzuwuchern. Die Neigung der primitiven Integumentverdickung, den organoiden Charakter einer Neubildung anzunehmen, ist hier deutlich $\mathrm{zu}$ erkennen.

Über die Verteilung der kopfständigen Neubildungen wurde im allgemeinen Teil bereits das Wesentlichste gesagt. Im Folgenden soll ihre Gestalt und ihr histologischer Bau an der Hand besonders typischer Falle geschildert werden.

\section{A. Organoide Formen.}

$\mathrm{Zu}$ den Neubildungen von organoidem Bau gehören in erster Linie fast alle lippenståndigen Neubildungen. Am normalen Stint befindet sich namlich an den freien Mundrandern ein lippenförmiger schmaler Wulst, der aus einer von Epithel überkleideten bindegewebigen Lamelle besteht. Dieser ist fast stets der Ausgangspunkt der Neubildungen und zwar entwickeln sich die Geschwülste in der Regel auf der nach aussen gerichteten Epithelfäche des Wulstes. Bei jungen solitären Formen lăsst sich dies bei der mikroskopischen Untersuchung einwandfrei erkennen. Es soll auch von Fall zu Fall darauf hingewiesen werden, weil die primäre Beteiligung der ausseren Epithelseite ein Indizium dafür darstellt, dass die Neubildungen sich vorzugsweise an besonders exponierten Gegenden entwickeln.

In den jüngsten Stadien, die ich beobachten konnte, stellen die lippenständigen Neubildungen weizenkorngrosse Gebilde dar. Sie befinden sich, wie ihr Name sagt, auf den freien Mundrändern. Schon früher (S. 210) babe ich darauf hingewiesen, dass der von der normalen Haut überaus abweichende Organisationstyp der lippenständigen Neubildungen eine ganz besonders grosse Anhäufung der für ihre Entstehung - notwendigen Reize vermuten lässt. So ist es vielleicht zu erklären; dass schon die kleinsten Formen einen ausgesprochenen Ansatz zur organoiden Ent- 
wicklung aufweisen. Zwei derartige Neubildungen sind auf Taf. XVII, Abb. 17 und 18, im Lăngsschnitt wiedergegeben. Die eine (Taf. XVII, Abb. 18) befindet sich am Ober-, die andere (Taf. XVII, Abb. 17) am Unterkiefer. Die Obertläche der ersteren ist eben, die der letzteren erodiert (Er). Die Erosionsfläche ist nach vorn zu gerichtet. Beide Neubildungen sind an der Ansatzstelle ringförmig eingeschnürt, ferner sehr kurz und noch ziemlich breitbasig gestielt. Ihre Langsachsen stehen fast senkrecht auf der Unterlage. In anderen Fällen können sie aber auch nach der Seite hin gerichtet sein. Der Tumor bildet dann sehr oft ein Hindernis für den Kieferschluss. In Taf. XVI, Abb. 4 und 5 sind zwei solcher Fälle dargestellt (x). Die Artikulation ist auch d a n n meistens behindert, wenn die Neubildung der Breite nach sebr stark entwickelt ist (siehe Taf. XVI, Abb. 6, x).

Der histologische Bau der beiden erstgenannten Neubildungen (Fig. 17 und 18) ist noch relativ einfach zu nennen. Die am Oberkiefer befindliche (Abb. 18) stellt eine enorme Verdickung des Lippenwulstes dar. Zwei Lamellen $\left(\mathrm{L}^{1}, \mathrm{~L}^{2}\right)$, welche vom bindegewebigen Anteil der Lippe ausgehen, durchsetzen eine dichte Epithelmasse (w. E). Diese entspricht teilweise der nach aussen zu liegenden Epidermisschicht des Lippenwulstes, denn das innere Epithel (i. E) sieht man in normaler Stärke verlaufen. Die obere Bindegewebslamelle $\left(\mathrm{L}^{2}\right)$ ist dick und kurz, die untere (L $\left.{ }^{1}\right)$ sehr lang. Sie reicht fast bis an die Oberfläche der Neubildung. Auf dem Wege dahin gibt sie Querlamellen (Ql) ab und bildet dadurch Fächer für das Epithel. Dieses liegt in jenen nestartig eingebettet (w. E). Auf der Abbildung 17, welche einen Lăngsschnitt durch die Neubildung am Unterkiefer zeigt, sind die bindegewebigen Fächer (Q1) quer getroffen. Auch hier ist die nach innen zu gelegene Epithelseite des Wulstes (i. E) normal und geht plötzlich in die dicke Epithellage des Tumors über. Sie kleidet die durch das bindegewebige Stroma gebildeten Wände in verschiedener Stärke aus und übertrifft dabei die der normalen Epidermis stellenweise um das 15 fache (w. E).

In den beiden Neubildungen sind die untersten Zellenlagen der nestartig angeordneten Epithelmassen (w.E) zylindrisch geformt. Weiter vom Stroma entfernt schichtet sich das Epithel in einer gewissen Ordnung, die der Druckrichtung entspricht, in welcher es nach dem Zentrum eines Faches zu proliferiert. Dabei ergeben 
sich die verschiedenartigsten Bilder, indem die Epithelzellen alle nur erdenklichen Formen annehmen. Häufig strecken sie sich spindlig, manchmal krümmen sie sich halbmondförmig und überholen sich dabei gegenseitig. In Winkeln, die durch abzweigende Querlamellen gebildet werden, liegen sie haufenweise wie an einem toten Punlst. Durch die Reibung mit anstossenden Epithelmassen, denen der Proliferationsweg in geringerem Maße oder überhaupt nicht versperrt ist, drehen sie sich wie im Wirbel und schichten sich dabei zwiebelschalenförmig. Bei älteren und grösseren Formen treffen wir sie in degeneriertem Zustand wieder. Hier bei den jungen Tumoren ist von regressiven Vorgängen noch wenig $z u$ sehen. Das Bindegewebe erscheint normal. Zahlreiche Gefässe durchsetzen es, besonders an der Ausgangsstelle der Neubildung vom Mutterboden. Sie haben ein weites Lumen und sind sehr dünnwandig. Auf die hierdurch bedingte leichte Verletzlichkeit sind wohl die Hämorrhagien zurückzuführen, die man besonders häufig bei den älteren Formen antrifft. Pigment ist ungleichmässig verteilt. In der kürzeren oberen Lamelle der an der Oberlippe befindlichen Geschwulst (Abb. 18) ist es reichlich vorhanden (P). Die Anhäufung gerade an dieser Stelle steht in erkennbarem Zusammenhange mit der starken Verbreitung des Pigments in dieser Kopfgegend überhaupt. Denn in der unteren Lamelle, welche dem pigmentfreien Corium des Mundes näher liegt, fehlt es ganz, desgleichen im Stroma der Neubildung am Unterkiefer (Fig. 17, Q1). Das Pigment liegt in dem in Taf. XVII, Fig. 18 dargestellten Falle in Chromatophoren, die sowohl im Gewebe der gesunden Haut wie in dem der Neubildung im ausgebreiteten Zustande konserviert worden sind (siehe Taf. XYIII, Fig. 19, P.)

Eine Zellform des Epithels, welche am Ïbergang des normalen zum gewucherten Epithel vorkommt, verdient eine besondere Beachtung. An dieser Stelle, die als Ausschnitt aus Abb. 18 (cf. die umrahmte Partie) in Abb. 19 stark vergrössert wiedergegeben ist, sieht man spindelförmige Zellen (s. E), deren Längsdurchmesser den der Breite ca. 15-20 mal übertrifft. Sie scheinen unter der Einwirkung eines ganz enormen seitlichen Druckes zu stehen, wie aus ihrer gestreckten Form und ihrem dichten Gefüge hervorgeht. Betrachtet man die Zellen unter noch stärkerer Vergrösserung, so zeigt es sich, dass sie mit 
ihrer Hauptachse nicht in einer Ebene liegen, sondern dass jene eine Kurve beschreibt, etwa wie eine halbe Windung einer flach verlaufenden Spirale. Der Kern der Zelle ist nicht verändert, wohl aber das Plasma. Hier fallen tief dunkle Zonen auf, welche der Kontur des spindligen nach beiden Enden stark zugespitzten Zelleibes eng anliegen und sich scharf gegen das innere Plasma absetzen. Verfolgt man die Zellen durch mehrere optische Ebenen, so kann man genau erkennen, dass es nichts weiter als durch die Färbung scharf differenzierte Grenzschichten sind, die das Plasma allseitig umgeben, wenn auch in ungleicher Stärke.

Was die Natur dieser Hülle anbetrifft, so scheint es sich um eine dem Zellplasma wesensgleiche Masse zu handeln, die ich daher im Sinne F. E. Schulzes als Crusta bezeichne. Nach dem Rande der Geschwulst hin und überall dort, wo die Zellen weniger dicht liegen, fehlt diese Bildung. Die spindlige Zellform und die Crustabildung erklären sich sehr einfach, sobald man den Druck des vorspringenden Unterkiefers auf die Neubildung in Betracht zieht. Dass die Druckverhältnisse die normale Zellform bestimmen, ist eine bekannte Erscheinung. So führt Heidenhain (1911) die Zellformen der einzelnen Epidermislagen auf seitliche Pressungen und senkrecht hierzu wirkende Spannungen zurück. Im vorliegenden Falle trifft der Unterkiefer den Tumor vorn an der flachen Mulde (M), die auf seiner Unterseite zu erkennen ist. Um nun die Wirkung dieses Druckes auf die betroffene Gegend (cf. die umrahmte Partie) einzuschätzen, muss man berücksichtigen, dass er durch Hebelwirkung dahin übertragen wird. Als den Drehpunkt des Hebels kann man sich leicht die Basis (b) der oberen Lamelle denken, welche den relativ am wenigsten verschieblichen Teil der Neubildung darstellt. Eine Linie (a b), welche die tiefste Stelle (a) der Mulde (M) mit dem Fusspunkt der Lamelle (b) verbindet, bezeichnet die Lage des Kraftarms; eine Linie (b c), welche den Fusspunkt (b) mit dem Zentrum (c) der betroffenen Zellpartie verbindet, die Lage des Lastarms. Kraftarm und Lastarm, die sich bei $b$ in einem stumpfen Winkel treffen, verhalten sich auf den einzelnen Längsschnitten durch die Neubildung verschieden. Es ergibt sich aber eine mittlere Proportion von etwa 8:1 zueinander. Der Druck des Unterkiefers an der Mulde (M) pflanzt Archiv f. mikr. Anat. Bd.87. Abt. I. 
sich somit auf jene Epithelgegend in ca. achtfacher Stärke fort. Die hier liegenden Zellen strecken sich infolgedessen spindelförmig. Dabei erfolgt die seitliche Pressung in der Druckrichtung, das Maximum der Spannung des Zellplasmas dagegen ist senkrecht hierzu gerichtet. Dass die Streckung der Epithelzellen in der Tat in der bezeichneten Richtung erfolgt, lehrt ein Vergleich der Präparate. Die eben auseinandergesetzte Druckwirkung, deren Orientierung auch an der aufwarts gerichteten Wachstumstendenz der bindegewebigen Lamellen $\left(\mathrm{L}^{1},{ }^{2}\right) \mathrm{zu}$ erkennen ist, entspricht jedoch nur einer Komponente der vorhandenen Druckkräfte. Diese bewirken nämlich nicht nur die seitliche Kompression der Epithelzellen, sondern auch ibre spiralige Drehung. Denn der Druck des Unterkiefers bewegt oder dreht vielmehr auch die Neubildung um eine Längsachse, welche im wesentlichen von der Medianlinie der oberen Lamelle gebildet wird $\left(\mathrm{L}^{2}\right)$.

Die Crustae dürften den plasmarandständigen Epithelfasern Kromaye $r$ s funktionell gleichwertig sein, zumal sie auch teilweise mit denen anderer Zellen in kontinuierlichem Zusammenhange stehen. Ihre Aufgabe ist demnach wohl darin zu erblicken, der enormen Längsspannung und der Zerrung entgegenzuwirken, der die Zelle einmal durch den seitlichen Druck, dann aber auch durch die Drehung ausgesetzt sind. Dafür spricht vor allem das Fehlen der Crustae am Rande der Gescbwulst und überall da, wo das Epithel keineriei Druckwirkungen unterliegt. Trotz der räumlichen Enge sind die Kerne normal gross und normal geformt. Ja, Mitosen, welche zahlreich anzutreffen sind, spielen sich derart ab, dass ihre Achse sich quer zur Längsachse der Zelle einstellt. Dieses Verhalten zeigt, dass der Kern von dem Druck gar nicht betroffen zu sein scheint. Die schützende Wirkıng der Crusta kommt hierdurch deutlich zur Geltung.

In manchen Fallen nimmt die Neubildung schon im jugendlichen Stadium einen blumenkohlartigen oder polypösen Charakter an. Er kommt dadurch zustande, dass der bindegewebige Anteil der Lippe eine Anzahl Lamellen entsendet, welche fortlaufend von einer dicken Epithellage überzogen sind. In Fig. 22 ist ein solcher Fall abgebildet. Die Risse im Epithel (w. E) sowie seine Abhebung von der Unterlage stellen postmortale. Veränderungen dar. Man erkennt einen zwischen Maxillare (Ma) und Prämaxillare 
(Pm) entspringenden Bindegewebswulst (s. B), welcher mehrere Seitenlamelien (Q1) abgibt. An der Ansatzstelle ist der Wulst stark verdickt und von zahlreichen Gefässen $(G)$ durchsetzt. Die nach innen zugewandte Epithelschicht der Lippe ist auch hier von normaler Stärke (siehe Abb. 22, Taf. XVII i. E), ein Beweis, dass die äussere Epithelseite genau wie in den früher betrachteten Fällen (Fig. 17 und 18), Ausgangsort der Neubildung ist. Der vordere Teil der Mundschleimbaut (Iv) ist im vorliegenden Fall (Fig. 22) ausnahmsweise isoliert in eine Neubildung umgewandelt worden und zwar nach Art der später noch zu erwähnenden Integumentverdickung. Das Epithel (w. E) des polypösen Tumors proliferiert in gleichmässigen Schichten, da es überall, wo es das Stroma überzieht, frei nach aussen führende Flächen besitzt. Auch hier finden wir im Bindegewebe der Neubildung Pigmentzellen eingelagert (P). Dieselben sind jedoch ebenso wie im Coriums der zunächst befindlichen Kopfgegend in kontrahiertem Zustande konserviert worden.

Schon auf einem so jungen Stadium, wie es der eben geschilderte Fall repräsentiert, können die Neubildungen im histologischen Bau Erscheinungen aufweisen, die an die Natur maligner Formen erinnern. So fand sich z. B. in einem hier nicht abgebildeten Falle eine erbsengrosse Neubildung an der Oberlippe eines Stintes. Dieselbe sass vorn dem Prämaxillare kurz gestielt, aber noch ziemlich breitbasig auf. Sie hatte sich auf den Unterkiefer zu entwickelt und wurde daher von den scharfen Zähnen desselben fortwährend verletzt. Eine tiefe Furche bezeichnet am konservierten Präparat diese Stelle und teilt den Tumor in zwei Teile. Der kleinere hintere Abschnitt, welcher zwischen den Zähnen des Maxillare und Dentale liegt, zeigt ein histologisches Bild, das der Quetschung entspricht, der der Tumor an dieser Stelle ausgesetzt ist. Ein regellos verlaufendes wabenförmiges Stroma ist voll angefüllt von Epithelzellen, die sich nach dem Druck schichten, den die Zähne beim Kieferschluss ausüben. Der vordere und grössere Teil der Neubildung dagegen ist nach oben zu gedrängt und liegt der Haut über dem Rostrum dicht an. In beiden Tumorhälften verlaufen die Epithelzapfen in unregelmässigen Windungen. Auf Schnitten, welche durch die Neubildung geführt sind, sieht man sie daher stets sowohl langs wie quer getroffen. Am vorderen Teil der Neubildung ist die dichte und ungeordnete 
Durchsetzung des Bindegewebes mit Epithelzapfen und Zellhaufen ganz besonders auffallend. Das Bindegewebe bildet hier nicht regelmässig verlaufende Lamellen, sondern stellt ein wirres Netz von Bindegewebszügen dar. Das Stroma der Neubildung ist überall von weiten, zartwandigen Gefässen erfüllt. Hämorrhagien sind darum keine Seltenheit. Die Epithelzellen zeigen stellenweise eine eigenartige Anordnung. Häufig liegen sie nämlich zwiebelschalenförmig geschichtet. "Man könnte sie" - um mich hier einer gelegentlich der Untersuchung der Karpfenpocken von M. Plehn gebrauchten Ausdrucksweise zu bedienen - „in der Tat mit Kankroidperlen vergleichen, wenn nur eine Spur von Verhornung vorhanden ware." Mitosen sind in den eingeschlossenen Epithelnestern zu beobachten; sie weisen jedoch keine $\mathrm{Ab}$ weichungen von den normalen auf.

Ein anderer bemerkenswerter Vorgang betrifft die Schleimzellen am vorderen Teil derselben Neubildung. Diese sind in der Geschwulst weder in der regelmässigen Verteilung noch in dem gleichen Mengenverhältnis wie in der normalen Epidermis anzutreffen. An manchen Stellen fehlen die Schleimzellen ganz. An anderen wiederum liegen sie $\mathrm{zu}$ hunderten haufenweise beisammen. Ihre Kerne sind dann meistens zerfallen. Vereinzelt findet man die Schleimzellen fast nur nach den Rändern der Yeubildung zu. Hier befinden sie sich auch dann noch im funktionstüchtigen Zustande.

Eine noch weiter vorgeschrittene Jeubildung veranschaulicht Taf. XVIl, Abb. 20 im Langsschnitt. Der Stint, dem sie angehörte, fiel dadurch auf, dass er den Mund nicht ganz schliessen konnte, obgleich äusserlich vorn am Rostrum nur ein etwa weizenkorngrosser Tumor zu sehen war. Bei der näheren Untersuchung zeigte es sich dann, dass auch die vordere Hälfte der Mundhöhle von einer etwa erbsengrossen Geschwulst erfüllt war. Beide Yeubildungen hängen zusammen und sitzen mit einer gemeinsamen breiten Basis dem Mundrande bezw. der Mundschleimhaut auf. Die Einkerbung, die an dem Punkt $\mathrm{M}$ in Fig. $20 \mathrm{zu}$ erkennen ist, wird durch den gegen den Tumor wie ein Keil andrängenden Unterkiefer (D) bewirkt. Der vom Unterkiefer ausgehende Druck bestimmt die Wachstumsrichtung der Neubildung, indem sich der vordere Teil nach oben, der hintere nach der Mundhöhle zu entwickelt. Der Unterkiefer selbst hat durch den steten Druck bei 
der Kieferschliessbewegung in der Gegend des Dentale eine Deformation erlitten, indem sein oberer Rand vorn übergeneigt ist.

Das histologische Bild der Neubildung deckt sich mit dem der vorhin beschriebenen. Es ist hier nur noch eine graduelle Steigerung der Destruktions- und Degenerationsvorgänge zu bemerken. Die Epithelzapfen (Ez) reichen fast bis an den Rostralknorpel (R). Sie sind hier von diesem durch eine Schicht straffen Bindegewebes getrennt (s. B). Die Verdichtung der Fibrillenzüge in der Bindegewebsschicht scheint sich im Sinne einer schützenden Reaktion gebildet zu baben. Das Stroma der Neubildung (L) enthält sehr reichlich Blutgefässe und macht beinahe den Eindruck einer Blutgefässgeschwulst, eines Hämangioms. Entsprechend dem vorgerïckten Stadium, in dem der Tumor sich befindet, ist die Vorderseite seiner oberen Hälfte so stark erodiert, dass sie auf dem Längsschnitt (Fig. 20, Er) tief zerklüftet erscheint. Das Auftreten der Erosionen auf der Vorderseite der Tumoren, die bei der Vorwärtsbewegung des Fisches leicht Insulten ausgesetzt ist, haben wir schon bei der in Fig. 17, Taf. XVII abgebildeten Neubildung beobachten können. Es erscheint mir von Wichtigkeit, auf dieses Verhalten besonders hinzuweisen, weil es in einer auffallenden Parallele mit $d e r$ Erscheinung steht, dass fast stets nur die Aussenseite des Epithels am Lippenwulst die primäre Ausgangsstelle für die Neubildungen darstellt.

Der in die Mundhöhle hineinragende Teil des Tumors (Fig. 20) besitzt eine ziemlich ebene Obertläche. Hier liegen die Epithelzellen in einem sehr lockeren Gefüge und zwar kommt dies um so mebr zum Ausdruck, je weiter der Abstand der Zelllagen rom Stroma ist. Auch hier steht das Gefüge der Zellen wohl in Beziehung zu der Druckwirkung; die vom Unterkiefer ausgeht. Im Gegensatz zu dem früher beschriebenen Fall, wo die Epithelzellen fest eingekeilt eine spindelförmige Form annehmen und zu der Crustabildung Anlass geben, haben hier die Zellen Platz zum Ausweichen. Das kommt an den besonders von der Quetschung betroffenen Partien durch die Lockerung des Zellverbandes zum Ausdruck. Dieser Vorgang wird gefördert durch die Lage des Tumors im Mundinnern.

In den festgefügten Partien des Epithels sieht man eine eigenartige Form von Epitheldegeneration, die in der Bildung von Hohlräumen und Auflösung von Zellen besteht. Die Er- 
scheinung erinnert an eine ähnliche, die. Löwenthal (1907) gelegentlich der Untersuchung der Karpfenpocken als „ballonierende" Degeneration beschrieben hat. ${ }^{\text {) }}$ Diese Degenerationsform habe ich nur noch bei den Neubildungsformen beobachten können, die eine Integumentverdickung darstellen. Dort werde ich sie auch ausführlicher beschreiben.

Vit $z u$ den imponierendsten Exemplaren aller von mir beobachteten Neubildungen gebören die auf Taf. XYI, Fig. 1, 3, 7 und 8 abgebildeten. Beide befinden sich an Stinten, welche tot ankamen und somit etwas spat zur Konservierung gelangten. In beiden Fällen sind es mächtige Tumorgebilde, von denen bei makroskopischer Betrachtung sich nicht sagen lässt, ob sie aus einem oder mehreren Einzeltumoren bestehen.

Der in Fig. 1 von der linken Seite und in Fig. 3 von oben her abgebildete Stintkopf weist vorn am Kopf eine bohnengrosse Geschwulst auf $(\mathrm{x})$. Durch schmale Furchen getrennt, von denen die eine die ehemalige Mundspalte andeutet, schliessen sich diesem Tumor zwei andere Geschwülste an. Ein erbsengrosser 'Tumor befindet sich nämlich vorn am Linterkiefer und ein ebenso grosser (y) links seitlich, welcher an den Mundründern entlang über die Mundwinkel hinweg bis zum Auge sich erstreckt, das er von unten her einrahmt.

Die Neubildung des anderen Stints weist noch mächtigere Dimensionen auf. Abb. 7 zeigt den Kopf von oben. Abb. 8 von unten. Ein monströses Gebilde sitzt vorn am Kopf. Es ist ein taubeneigrosser Tumor, welcher rechts und links enorm ausladet. Oben erstreckt er sich bis $\mathrm{zu}$ den Naseneingängen, seitlich bis zu den Mundwinkeln. Zwei Hauptfurchen durchqueren ihn. Die obere, welche ganz vorn verläuft, stellt den Zugang zur Mundhöhle, die Mundspalte, dar. Diese ist somit aus ihrer natürlichen Lage vollkommen verschoben. Sie scheidet das monströse Gebilde in zwei Teile, in einen mächtigeren Abschnitt, welcher dem Unterkiefer angehört $(\mathbf{x})$, und in einen kleineren, welcher den Oberkieferknochen vorn aufsitzt $(y)$. Der Übergang

1) Löwenthal versteht unter "ballonierender Degeneration" die „Auflösung von Zellen mit Bildung kleiner mit Detritus gefüllter Hohlräume". Es handelt sich hier wohl um eine Degenerationsform, die auch beim Menschen in gewissen Epithelhyperplasien auftritt und als "Physalide“ wiederholt beschrieben wurde. 
der Neubildung in die nicht veränderte Haut vollzieht sich am Unterkiefer ganz allmählich und wird nur durch zarte Rinnen angedeutet. Am Oberkiefer dagegen setzt sie sich wallartig und mittels einer klaffenden Furche $(z)$ gegen die gesunden Nachbarbezirike ab.

Auch die histologische Untersuchung lässt erkennen, dass wir bei beiden Stinten Tumorgebilde von aussergewöhnlichen Dimensionen vor uns baben. Auf der Abb. 21, Taf. XVII, welche dem zuletzt beschriebenen Fall angehört und einen Sagittalschnitt durch die linke Kopfhälfte darstellt, erkennt man zwei Neubildungen, eine am Ober- und eine am Unterkiefer.

Die kleinere gehört dem Oberkiefer an. Sie sitzt breitbasig dem vorderen Kopfrande auf und erstreckt sich von der Hautschleimhautgrenze der Mundspalte bis zur Nase. Das Bindegewebe, welches Prämaxillare (Pm) und Maxillare (Ma) verbindet, ist stark verdickt (s.B). Es sendet eine Anzabl Lamellen (L) in eine machtige Epithelmasse hinein (w.E). Die Organisation des Tumors entspricht den in Fig. 17 und 18 beschriebenen. Der dichte bindegewebige Strang (s. B), welcher von dem vorderen Rande der Nasengrube bis übers Maxillare hinaus sich in die Neubildung hinein erstreckt, ist der Weg, auf dem das Pigment (P) in diese eingewandert ist. Auffallend ist eine beträchtliche Verlagerung der Knochen- und Knorpelteile der Oberkiefer- (Pm, $\mathrm{Ma}, \mathrm{R}$ ) und Palatinreihe (Pa). Sie sind in einer seichten, nach oben zu offenen Kurve verschoben. Hierdurch und infolge der Wucherung des Bindegewebes, welches sich zwischen der vorderen Nasenwand und dem Maxillare befindet, ist die Nasengrube beengt, ohne dass sie aber selbst in die Neubildung mit einbezogen wäre. Der Boden der Nasengrube, welcher normalerweise an dieser Gegend beinahe parallel zur Oberfläche des Kopfes verläuft (vgl. Taf. XVII, Abb. 22, Na), ist schief nach unten gerichtet (Fig. 21, Na) und steht fast senkrecht auf dem Rostralknorpel (R).

Diese ganze Erscheinung wird durch den Druck der gewaltigen Tumormasse bewirkt, die dem Unterkiefer angehört. Sie sitzt ihm mittels eines mächtigen Stieles (St) auf, welcher aus dem Lippenwulst hervorgegangen ist. Er ist auf der $\mathrm{Abb} .21$ im Längsschnitt getroffen. Weitlumige Gefässe $(G)$ durchziehen in grösserer Menge den Stiel und verbreiten sich in die un- 
zähligen Längs- (L) und Querlamellen (Ql), die das Bindegewebe in die Geschwulst hineinsendet.

Auch bei einem lebenden Stint konnte ich einen derartigen Stiel beobachten, welcher nicht wie im vorliegenden Falle durch die daran befindliche Geschwulst völlig verdeckt war. Durch das ihn durchströmende Blıt sah er dunkelgefärbt aus, und man konnte ein leichtes Pulsieren an ihm wahrnehmen. Er hob sich ganz deutlich von der milchglasfarbigen übrigen Tumormasse ab.

Vom Ende des Stieles, welcher in dem hiel. (Fig. 21) vorliegenden Falle schräg nach unten verliuft (St), nehmen die bindegewebigen Querlamellen (Ql) ihre Wachstumsrichtung nach oben. Der Wachstumsdruck der unteren Neubildung bewirkt zunächst, dass die gegenüberliegende Geschwulst am Oberkiefer, die - ihrem viel kleineren Volumen nach zu urteilen - jüngeren Datums ist als die am Unterkiefer, nach oben und hinten gedrängt wird. Hierdurch kommt die vorhin erwähnte Verlagerung der Oberkiefer- (Pm, Ma, R) und Palatinreihe (Pa), sowie die Einengung der Nasengrube (Na) zustande. Andererseits setzt sich der Druck aber auch auf den Stiel (St) fort, dessen Länge und mächtige Entwicklung wohl als die Einwirkung des steten Druckes im Sinne eines trophischen Reizes gedeutet werden kann.

Hier bei diesem Tumor am Unterkiefer verdient ein eigenartiges Verhalten der bindegewebigen Lamellen eine besondere Würdigung, um so mehr, als es sich um eine Erscheinung handelt, die man häufig auf Lăngsschnitten durch umfangreiche Stintneubildungen beobachten kann und die uns später noch einmal begegnen wird. In weit stärkerem Maße nämlich als es bei dem in Fig. 20 abgebildeten und früher schon beschriebenen Tumor zutrifft, dienen bier die Bindegewebslamellen (QI, L) der Blutversorgung. Ist somit schon ihre reiche Terteilung in dem vorliegenden Tumor bemerkenswert, so ist sie es erst recht durch die Art, in welcher sie erfolgt. Die bindegewebigen Querlamellen (Q1) stehen fast durchweg mit ihren Längsachsen senkrecht zu der Epithelfläche (v) des Tumors, welche den Druck auf die gegenüberliegende Neubildung vermittelt. Dabei băngen die Lamellen (Ql) durch Verbindungsstücke zusammen, an welchen die vom Druck am meisten betroffenen Teile des Tumors derart aufgehängt sind, dass ein auf diese wirkender Druck vermittels dieser Verbindungsstücke auf die benachbarten Querlamellen und 
somit auch auf die übrige Epithelmasse der Neubildung übertragen wird. So ist z. B. der in der Mitte befindliche und besonders umrabmte Teil (U) in der vorliegenden Abb. 21 durch ein solches Aufhängesystem ausgezeichnet. Mit (Q1) sind die Querlamellen, mit (Vb) die Verbindungsstücke bezeichnet.

Die gekennzeichnete Einstellung des Epithels und des Bindegewebes dürfte vielleicht die vorteilhafteste Entwicklungsmöglichkeit der Neubildung gewăhrleisten. Offenbar wird hierdurch dreierlei erreicht.

Zunächst wird die Neubildung als Ganzes gleichmässig von dem Druck in Anspruch genommen. Es übertragen nämlich wie oben angedeutet - besonders belastete Teile des Tumors den auf sie ausgeübten Druck auf die übrigen minder beanspruchten Partien der Neubildung.

Ferner wird die Blutversorgung aufrecht gehalten. Dies könnte nicht der Fall sein, wenn die Querlamellen (Ql) senkrecht zur Druckrichtung - in der vorliegenden Neubildung also horizontal - verlaufen würden. Sie würden dann nämlich durch den von oben her wirkenden Druck komprimiert werden. In diesem Falle aber wäre die Ernährung der Neubildung und ibr weiteres Wachstum vollstandig in Frage gestellt.

Schliesslich erscheint die besprochene Einstellung der Querlamellen (Ql) von grösster Bedeutung für eine ausserst zweckmässige Druckverteilung im Epithel selbst. Letzteres wird durch die Lamellen in Blöcke geschieden. Diese stellen auf Längsschnitten durch den T'umor oblonge, meist vier- oder fünfeckige Felder dar (siehe Abb. 21, x, y, z). Die Epithelblöcke entsprechen den schon auf früheren Stadien erwähnten Epithelmassen, welche - wie Parenchym im Stroma eines Organs - in den bindegewebigen Fächern eingelagert sind. Der Längsdurchmesser (a) des oblongen Feldes, das dem Epithelblock $x$ angehört, verläuft mit der Druckrichtung. welche durch den vertikalen Pfeil ( $\left(\begin{array}{l}\uparrow \\ 1\end{array}\right)$ angedeutet ist, und mit den Querlamellen (Ql) parallel, sein Breitendurchmesser (b) liegt in der Horizontalen, die durch einen entsprechenden Pfeil $(\rightarrow)$ bezeichnet ist. Die grössere Măchtigkeit in der Druckrichtung sichert dem Epithelblock eine grössere Festigkeit in dieser als senkrecht dazu. Gleichzeitig wächst auch hierdurch seine Elastizität. Beide Eigenschaften sind in der Horizontalen nicht so nötig wie dort, da hier nur geringe Spannungen herrschen. Die Kräfte, welche diese 
darstellen, resultieren einmal aus der seitlichen Verschiebung der einzelnen Epithelzellen unter der Einwirkung des Druckes von oben her. Ferner wirken Zugkräfte, die von benachbarten belasteten Epithelblöcken ausgehen und durch Verbindungsstücke vermittelt werden. Da sich nun aber die seitlichen Spannungen aller Epithelblöcke ziemlich in einer Ebene -- der Horizontalen bewegen und entgegengesetzt wirken, so kompensieren sie sich zum grössten Teil. Diese Druckkompensationen sind aus dem geraden Verlauf vieler Querlamellenabschnitte (Ql) deutlich zu erkennen.

Nicht immer liegen die Druck- und Zugverhältnisse so klar wie bei dem besprochenen Epithelblock $\mathrm{x}$. Manchmal sind sie in einer Linie $z$ u suchen, die der Resultante zweier Komponenten entspricht. Diese können durch zwei im Winkel zusammenstossende Teile von Querlamellen gebildet werden (vgl. das Feld y mit den Querlamellenabschnitten $Q l_{1}$ ). In anderen Fallen bilden Teile von (Querlamellen und Verbindungsstücke die Komponenten, aus denen sich als Resultante die Druckrichtung ergibt, wie z. B. im Feld $z$, wo $\mathrm{Ql}_{2}$ die (Querlamelle, $\mathrm{Vb}_{1}$ das Verbindungsstück bedeutet. Querlamelle und Verbindungsstück können streckenweise für einander eintreten und somit ihre Funktionen wechseln. Die Anordnung der Querlamellen (Ql) und ibrer Verbindungsstücke (Vb) nach den dargelegten Prinzipien dürfte als eine Schutzreaktion der Teubildung aufzufassen sein und spricht für ihren selbständigen - organoiden - Charakter.

Der im Laufe des Wachstums des Tumors immer stärker werdende Druck in der Vertikalen hat auch den Unterkiefer (D) in Mitleidenschaft gezogen. Er hat sich an der abgebildeten. Stelle um ca. $60^{\circ}$ nach aussen gedreht.

Geschwülste von der eben beschriebenen Grösse gehören durchaus nicht zu den Seltenheiten.

Der grösste Tumor, der mir zu Gesicht gelangte, gehört - ebenso wie die vorhin erwähnten - einem ausgewachsenen Stint an, den ich lebend eine Zeitlang beobachten konnte. Hier war der ganze Kopf in ein Gebilde von abenteuerlicher Form umgewandelt. Nur ein Teil der Augen und des oberen Schädeldaches waren frei sichtbar. Der übrige Teil der Kopfobertläche wurde von milchglasartig durchscheinenden Tumormassen eingenommen, welche nach allen Seiten hin ungleich grosse Aus- 
ladungen aufwiesen. Durch tiefe Furchen waren sie unregelmässig zerklüftet. Trotzdem der Fisch in seiner Nahrungsaufnahme ganz erheblich beeinträchtigt war, zeigte er eine kräftig entwickelte Gestalt und rege Schwimmlust. In der Atembewegung bewies er auch keine auffällige Unruhe. Dagegen gebärdete er sich ausserst erregt, wenn er an die Glaswände des Aquariums anstiess. Bald nach seinem Eintreffen war ein kleines Probestück der Geschwulst exzidiert und fixiert worden. Der ganze uibrige Fisch wurde fast unmittelbar nach seinem am nächsten Tage erfolgten Tode konserviert.

Bei der histologischen Untersuchung zeigte es sich, dass das monströse Gebilde aus einer grossen Anzahl von Einzeltumoren in verschiedener Grösse und Form bestand.

In dem abgebildeten Transversalschnitt durch den Kopf (Taf. XVII, Fig. 10) sieht man allein vier grosse Neubildungen. Zwei riesige Tumoren, welche die Maxillaria (Ma) beiderseits vollständig umgeben, reichen über den infraorbitalen Kanal der Seitenlinie (i.S) hinweg bis zum Naseneingang, wo sie sich als Integumentverdickungen (Iv), die später noch genauer beschrieben werden, fortsetzen. Der rechte Tumor erstreckt sich noch tief bis in die Mundhöhle hinein, die er zusammen mit einer etwa gleichgrossen Geschwulst, welche sich über dem linken Palatinum (Pa) befindet, fast vollständig ausfüllt. Ausserdem hängt noch eine mächtige Neubildung vom rechten Unterkieferrande herab (D). Daneben befinden sich noch am Kopf eine Anzahl kleinerer und zum Teil ebenso grosser Tumoren, die auf dem abgebildeten Schnitt nicht getroffen sind. Zusammen mit den eben geschilderten verursachen sie das monströse Aussehen des ganzen Kopfes.

Von den Komponenten, die die Geschwülste zusammensetzen, ist das Verhalten des Bindegewebes von besonderem Interesse. An den Stellen, wo. es die Knochen umgibt oder sie miteinander verbindet, ist es auffällig verdickt (siehe Abb. 10, s. B).

Am interessantesten ist aber die Deformation, die der Tumor am Kopfskelett bewirkt hat. Hier fälit zunăchst das trotz der Ruhelage weit gesperrte Maul und die seitliche Verschiebung des Unterkiefers nach links auf. Man kann sich denken, dass der Stint zunächst durch das mächtige Wachstum der in der Mundhöhle befindlichen Neubildungen zur ständigen Offenhaltung 
des Maules gezwungen wurde. Um noch mehr Raum zu schaffen, musste der Unterkiefer dann seitlich nachgeben. Diese Seitenbewegung bestand aber lediglich in einem Reiten des rechten Unterkieferrandes (D) auf der gegenüberliegenden Neubildung. Der Unterkiefer konnte diese Bewegung um so leichter ausführen, da seine in der Ruhestellung vorhandene Fixierung durch die Maxillaria (Ma) bei der Sperrung des Maules fortfiel, und die weitere (̈ffnung desselben schliesslich auf mehr Widerstand stiess als die Bewegung des Unterkiefers nach der Seite hin. Auch die Maxillaria (Ma) sind verlagert. Die wuchernde Tumormasse hat sie von der Palatinreihe (Pa) abgedrängt. Hierbei tritt nun, wie das histologische Bild zeigt, der selbständige, organoide Charakter der Neubildung wiederum sehr deutlich zutage. So sind die Epithelblöcke (w. E) und die Bindegewebslamellen (L) der am linken Maxillare befindlichen Neubildung, welche den Druck des seitlich sich bewegenden Unterkiefers auf das Maxillare (Ma) vermitteln, in sehr zweckmässiger Richtung eingestellt. Die Bindegewebslamellen zeigen nämlich eine Gitterkonstruktion derart, dass bei der Seitwätsbewegung des Unterkiefers die Lamellen auf Zug: die eingelagerten Epithelblöcke auf Druck beansprucht werden. Es wird auf diese Weise eine Deformierung der Geschwulst verhindert. Wührend sich so die Neubildung in einer für sie selbst zweckmüssigen Art entwickelt, zieht sie aber bei jeder Seitenbewegung des Unterkiefers das linke Maxillare (Ma) von der Palatinreihe ab, wobei sie von einer zwischen Maxillare (Ma) und infraorbitalem Seitenkanal (i. S) mächtig dazwischen wuchernden Epithelmasse (V) wesentlich unterstützt wird. Der rechte Ast des Unterkiefers (D) ist ebenfalls deformiert. Da er mit seinem oberen Rande fast ganz allein den vertikalen Druck vermittelt, beginnt er eine Querlagerung anzunehmen. Mit diesem Druck hängt auch das nach abwärts gerichtete Wachstum der von seinem Rande ausgehenden Nellbildung zusammen.

Die drei letzterwähnten Tumoren (siehe Fig. 1, 3-7, 8$21-10)$ stehen sich einander sehr nahe. Das kommt nicht nur in ihrer äusseren Form und in ihrer histologischen Organisation zum Ausdruck, sondern auch in einem typischen Verhalten der Epithelzellen. Diese schichten sich in den Fächern des Stromas zu einer Epithellage, die die normale Epidermis um das drei- 
bis fünffache übertrifft. Alle Zellen sind zylindrisch geformt und säulenartig aufeinandergeschichtet (siehe Taf. XVIII, Abb. 9, w. E). Weiter zur Mitte zu - von der Epithellage durch eine deutliche Gewebslücke (Gl) geschieden - trifft man auf eine Schicht unregelmässig angeordneter Zellen ( $Z$ ). Soviel lăsst sich aus ihrer Gruppierung erkennen, dass sie dem Ausführungsgang eines Faches zustreben. Mehrere von ihnen sind dabei zu einem Gebilde von annühernd Kugelgestalt zusammengeschichtet, das an die früher erwähnte zwiebelschalenförmige Anhäufung von Epithelzellen erinnert. Hier ist das Zellplasma - unter Erbaltung der räumlich geschiedenen Kerne - in auffälliger Weise zu einer mehr oder minder homogenen Masse konfluiert. Cndeutliche Plasmagrenzen zeigen noch hier und da die ehemalige Form der Zellen an. Die Kerne selbst haben in solchen Zellgruppen eine randstindige Stellung eingenommen. In der Mitte fast jeder Zellgruppe befinden sich nun fast überall ein oder mehrere Klumpen. Sie sind scharf konturiert, durchweg von fast kugelförmiger Gestalt, aber verschieden grossem Volumen. Die kleinsten besitzen die normale Kerngrösse, die mächtigsten ibren achtfachen Durchmesser. Sie fürben sich mit Böhmers Hämatoxylin oder Hämalaun dunkelblau und nehmen bei nachfolgender van GiesonFärbung einen gelblichen bis orangefarbenen Ton an. Bei starker Vergrösserung beobachtet man, dass sie sehr häutig von einem Strahlenkranze umgeben sind. Nach Art eines Morgensterns sendet nämlich der Klumpen spitze Fortsätze in die Plasmamasse hinein. Dieses Phänomen ist bei den kleineren Einschlüssen sehr deutlich wahrzunehmen und tritt bei den allergrössten etwas mehr zurück. Eine feine helle Zone, die allmählich im Plasma verschwindet, umgibt jeden Einschluss. Die Kerne selbst weisen keine Veränderungen auf. Nur in den Făllen, wo die in der Vitte eines Faches befindliche Zellanhäufung einer totalen Degeneration entgegengeht, zeigen sie das Bild der Chromatolyse. Dann ist aber auch die ganze Zellschicht durch eine besonders. breite Gewebslücke von der funktionstüchtigen Epithellage geschieden. Nach den Rändern der Neubildung zu kann man diese. Einschlüsse ebenfalls antreffen. Sie verhalten sich ähnlich wie die in der Mitte eines Faches befindlichen. Die radiäre Strahlung. ist hier jedoch nicht vorhanden oder nur andeutungsweise ausgeprägt. Einzelne besonders grosse Einschlüsse zeigen Einschnü- 
rungen. Es sieht dann aus, als ob kleinere Klümpchen zu einem grossen zusammenfliessen wollten.

Diese Einschlüsse erinnern durchaus an die eingangs erwähnten Befunde Plehns (1906), die sie in den Kiemenepithelwucherungen mancher Salmoniden gemacht hat. Auch Löwen th al (1907) hat gelegentlich der Untersuchung der Karpfenpocken ähnliche Zelleinschlüsse beobachtet: "Sie sind meistens kugelig und vollkommen homogen. - Nur sehr selten zeigen sie am Rand eine Radiärstreifung. Bei Anwendung des Farbengemisches von van Gieson färben sie sich intensiver und in reinerem Gelb als das Protoplasma."

Eine Deutung der Klumpen in den Kiemenepithelwucherungen im Sinne der Chlamydozoentheorie, wie sie Keysselitz (1908) zur Erklürung gewisser Kerneinschlüsse in Epithelzellen von Lippenepitheliomen mancher Barben herangezogen hat, lehnt schon Plehn (1909) vollständig ab. "Natürlich waren die merkwürdigen Zelleinschlüsse eine kräftige Anregung. im Anschluss an Provazeks Hypothese nach Parasiten zu suchen. Alle Bemühungen waren aber vergebens. Gebilde, die sich mit einiger Wahrscheinlichkeit als Parasiten batten deuten lassen, sind nicht vorhanden." Über die chemische Natur der. Einschlüsse aussert sich M. Plehn nur sehr zurückhaltend: „Es müssen Plasmaausscheidungen sein; vielleicht ist etwas chromatische Substanz hineingelangt und diffus darin verteilt, vielleicht beruht die Färbbarkeit aber auch auf der physikalischen Beschaffenheit. Die Kugelform der Einschlüsse selbst, sowie der in ihnen enthaltenen Vakuolen lässt darauf schliessen, dass sie flüssig sein müssen; sie verhaiten sich wie Tropfen."

Auch ich konnte in den Zelleinschlüssen beim Stint keine Gebilde entdecken, die etwa wie die von $\mathrm{Keysselitz}$ bei dem Lippenepitheliom der Barben beschriebenen für kleinste parasitäre Gebilde angesehen werden dürfen. Es fehlt somit ein Anbalt dafür, die Einschlüsse als Reaktionsprodukte der Zellen auf das Eindringen eines Mikroorganismus aufzufassen. Bei heys selitz handelt es sich überdies um Vorgänge, die sich im Innern des Kernes abspielen, wobei eine Wechselbeziehung zwischen den fraglichen Gebilden und dem Chromatin des Kernes statthaben soll. Die Zelleinschlüsse in den Stintneubildungen sind dagegen stets nur ausserhalb der Kerne im Plasma anzutreffen. Im Kerne 
selbst sind keinerlei auffällige Strukturen zu beobachten. Es ist sehr wahrscheinlich, dass die Einschlussklumpen aus "Hyalin“ bestehen. Sie dürften wohl dem von Lubarsch (1903) als "sekretorisches oder intracelluläres Hyalin" bezeichneten Umwandlungsprodukt entsprechen. Dafür spricht das fürberische Verhalten und die auf flüssige Konsistenz hinweisende Tropfenform der Einschlüsse. Die Bildung der Klumpen scheint sich in der Weise zu vollziehen, dass das Plasma einer Anzahl verschmolzener Zellen an einigen Stellen in Hyalin übergeht und dann in der durch die strahlenförmigen Fortsätze angedeuteten Weise in der Mitte des gemeinsamen Plasmas zu einem Klumpen zusammentliesst.

Eine Geschwulstbildung, welche durch eine dabei eingetretene Verwachsung der Ober- und Unterkiefer ein besonderes Interesse erregt, möchte ich noch erwähnen. Man sieht am konservierten Präparat, wie ein erbsengrosser Tumor aus der rechten Seite der Mundspalte ragt, gleichsam, als ob er unter dem Drucke der Kiefer hervorquillt. Dabei bedeckt er den Oberund Unterlippenrand zu einem grossen Teil.

Das mikroskopische Bild (Abb. 24, Taf. XVIII), zeigt einen Längsdurchschnitt durch die Geschwulst. Der ventrale Teil des Lnterkiefers (D) ist abgeschnitten, um senkrechte Schnitte zu dem abgebildeten zu erlangen und fehlt darum auf der Fig. 24. Hier erkennt man, wie von jedem Lippenwulst - von der Unterlippe mehr als von der gegenüberliegenden - bindegewebige Lamellen (L) entspringen, die sich ungefähr im Zentrum des Tumors begegnen. Das Stroma hat darum eine andere Anordnung erfahren als in den bisherigen Fällen, ebenso die Epithelzapfen (Ez). Die Hauptrichtung der letzteren sowie die der Lamellen (L) verläuft von der Witte der Neubildung radiär nach allen Richtungen. Trotz des autonomen Charakters des Tumors, der sich in der V'erwachsung zweier gegenüberliegenden Einzelneubildungen aussert, ist von einem tieferen Eindringen des Epithels in die gesunde Uimgebung oder gar von Metastasen nichts zu beobachten.

Die aufgeführten papillomatösen Formen stellen das Hauptkontingent aller orga noiden kopfständigen Neubildungen vor. Nur in zwei Fällen befinden sich am Kopf organoide Formen von jenem cystenartigen Bau, wie er für das ältere Stadium der 
flossenständigen Neubildung charakteristisch ist. Ihr histologischer Bau entspricht völlig dem der cystenartigen Neubildungen an den Flossen.

\section{B. Primitive Formen.}

In manchen Făllen ähnelt die Organisation einiger Hautneubildungen am Kopfe - selbst noch auf älteren Stadien dem primitiven $\mathrm{Bau}$, den die flossenständigen pockenartigen Epithelwucherungen aufweisen. Allerdings handelt es sich dann nicht nur um eine reine Epithelverdickung - wie bei jenen sondern meistens ist auch gleichzeitig das Corium stark verdickt. Ähnlich wie die Haut wird auch die Schleimhaut in grösserer Ausdehnung ergriffen. Doch ist in letzterem Falle fast durchweg ein Zusammenhang mit der Haut zu konstatieren.

Auf der Haut geht die Neubildung mit Vorliebe von den Mundwinkeln aus. Ein Fall, der hier nicht abgebildet ist und den ich mit Nr. 1 bezeichne, interessiert durch die mächtige Ausbreitung des Tumors. Er erstreckt sich vom rechten unteren Augenrande um den Unterkiefer herum bis zum UnterkieferSeitenkanal der gegenüberliegenden Seite. Während die Neubildung diesen Seitenkanal noch nicht ergriffen hat, setzt sie sich in den rechten Unterkiefer- und Infraorbital-Seitenkanal fort. Die höchste Erhebung der Neubildung befindet sich genau über dem Mundwinkel. Von hier aus fällt sie tlach $a b$ und geht allmählich ohne deutliche Grenze in das normale Epithel über. Die Silhouette des betroffenen Kopfteiles entspricht der "einer geschwollenen Backe".

Histologisch stellt sich die vorliegende Neubildung vorwiegend als eine mächtige Epithelverdickung dar. Das Corium weist nur an der Innenseite des Maxillare und in der Hautfalte, die den Mundwinkel bildet, eine Verdickung auf. $\mathrm{ES}_{\mathrm{S}}$ ist von Interesse, dass an diesen Stellen - ähnlich wie bei jungen organoiden Formen - bindegewebige Fortsătze in die Epithelmasse einzuwachsen beginnen. Sowohl bei der Hautfalte des Mundwinkels wie der Innenseite des Maxillare handelt es sich um Stellen, die bei der Kieferbewegung einer ständigen mechanischen Reizung ausgesetzt sind. Für den Übergang einer primitiven Neubildung in eine solche von organoider Form ist daher der mechanischen Reizung vielleicht eine Bedeutung bei- 
zumessen. Das histologische Bild zeigt hier ein wirres Durcheinander von Fibrillenzügen und Epithelzapfen und -nestern. Es sieht aus, als ob das Epithel in das Corium hineingewuchert wäre. Am linken Naseneingang macht die Neubildung Halt. Sie endigt hier mit einer reinen Epithelverdickung.

Aus einer Integumentverdickung von der eben geschilderten Form scheint auch die Neubildung hervorgegangen $\mathrm{zu}$ sein, die sich an der rechten Seite des Unterkiefers (D) befindet, welcher dem in Fig. 10, Taf. XVII abgebildeten und früher schon beschriebenen Stintkopf angehört. Hier beobachtet man, wie das mächtig verdickte Corium des Unterlippenwulstes (s. B) feine Ausläufer (L) in die aufgelagerten Epithelmassen (w. E) hineinsendet.

Zwischen Maxillare und infraorbitalem Seitenkanal legt sich am normalen Tier das Epithel streckenweise in Form einer Falte hinein. Wird diese in den Bereich einer Neubildung mit einbezogen, so wandelt sie sich stets in eine homogene Epithelschicht um, indem die beiden Epithellagen mit den einander zugewandten. Flächen verschmelzen. Auf dem in Abb. 10 wiedergegebenen Stintkopf tritt diese Erscheinung beiderseits deutlich hervor (V).

In dem vorhin erwabnten Falle Nr. 1 hat diese Verschmelzung der Flächen der Epithelfalte ebenfalls stattgefunden, aber dabei zu wichtigen Konsequenzen geführt. Die Epithelzellen sind in ein reges Wachstum eingetreten und so finden wir sie bereits in der unmittelbaren Umgebung des Seitenkanals vor, wohin sie in Gestalt von Epithelzapfen hineingewuchert sind. Abb. 27, Taf. XVIII zeigt einen Querschnitt durch den infraorbitalen Seitenkanal (i. S), Hautepithelverdickung (w. E) und die in das Corium hineingewucherten Epithelzapfen (Ez). Es erscheint naheliegend, dass der stete Druck, welchen die Verdickung der Epithelfalte zwischen dem Maxillare und dem infraorbitalen Seitenkanal (i. S) hervorruft, das rege Wachstum der Epithelzellen veranlasst hat.

Bei einem andern Stintkopf, den ich kurz als Nr. 2 bezeichnen möchte, hat sich die Neubildung ebenfalls als Integumentverdickung entwickelt. Hier befindet sich ihre höchste Erhebung am linken hinteren Maxillarende. Auch in diesem Fall zeigt das Epithel offenbar eine starke Wachstumstendenz. Auf dem in Fig. 26, Taf. XVIII abgebildeten Querschnitt kann man verfolgen, 
wie es zunächst eine Strecke weit als eine Epithelverdickung (w. E) verläuft. Es buchtet sich dabei stellenweise in das Corium vor, welches sich an der Grenzschicht stärker als normal zu einer straffen bindegewebigen Lage (s. B) verdichtet. Diese Erscheinung ist erst recht ausgeprägt in der Umgebung des mächtigen Epithelzapfens (Ez), der sich plötzlich in die Tiefe senkt.

In einer dritten Neubildung, die auch eine Integumentverdickung darstellt, sieht man eine Degenerationsform, welche eine grosse Ähnlichkeit mit einer "Physalide“ besitzt. Wie aus Abb. 23, Taf. XVI ersichtlich ist, bildet hier das Epithel (w. E) einen Hohlraum (H). Er ist von Flüssigkeit erfüllt und schliesst einen Haufen degenerierender Epithelzellen (d. E) ein, welche in den verschiedensten Stadien der Chromatolyse sich befinden. Mit Zunahme der Flüssigkeitsmenge übt diese offenbar einen immer starkeren Druck auf die unmittelbar anliegenden Epithelzellen aus. So dürfte deren spindelförmige, abgeplattete Gestalt (s. E) wohl am ehesten zu erklären sein. Der Druck scheint sich aber auch auf das Corium fortzuptlanzen, welches sich an dieser Stelle zu einer flachen Mulde (M) vertieft.

Ein bemerkenswertes Verhalten zeigen die Epithel- bezw. Integumentverdickungen, sobald sie auf der Conjunktiva oder der Schleimhaut der Nase und der Seitenkanaile auftreten.

Bei dem unter Nr. 2 beschriebenen Stintkopf setzt sich die Epithelverdickung der Haut (Fig. 12, Taf. XVIII) auf die Conjunktivalfalte $(C)$ fort, die sich zwischen dem infraorbitalen Seitenkanal (i. S) und dem Augapfel befindet. Hier hat sich auch das Bindegewebe eigenartig beteiligt, indem es vielleicht infolge des zunehmenden Druckes, welcher zwischen Auge und Epithelverdickung statthat, in die Epithelverdickung (C) hineingewuchert ist und sich dort gitterförmig verzweigt hat (g).

Die eigentümliche Art der gitterförmigen Verästelung hängt auch mit der Epithelwucherung des infraorbitalen Seitenkanals (i. S) zusammen, der ebenfalls in die Integumentverdickung der Haut mit hineinbezogen ist. In diesem und ăhnlichen Fällen wuchert zunächst das Epithel, welches unter normalen Verhältnissen als relativ schmale Schicht das weite Lumen des Seitenkanals umgibt, in das Lumen des Kanals hinein. Sehr bald kommt es dabei zu einer lückenlosen Ausfüllung desselben. Das Sinnesepithel, welches hier normalerweise reichlich vorhanden ist, 
verschwindet sehr bald. Es geht unter dem herrschenden Drucke entweder zugrunde oder wandelt sich in das weniger differenzierte Plattenepithel um. Bei dem riesigen Tumor, der auf der Figur 10 abgebildet ist, sieht man links einen Querschnitt durch einen derart umgeformten infraorbitalen Seitenkanal (i. S), während rechts gerade der Kommunikationsweg (Cw) getroffen ist, auf dem die Neubildung auf das Epithel des Seitenkanals übergegriffen hat. Auch Abb. 30, Taf. XVIII, zeigt den infraorbitalen Seitenkanal in gleichem Zustande. Die gewucherte Epithelmasse kleidet ihn in Form eines homogenen Zylinders aus (i. S).

In dem in Fig. 12 abgebildeten Fall ist die Epithelwucherung schon älteren Datums. Auch hier ist der Kommunikationskanal der Weg, auf dem sie sich von der Haut her in den Seitenlianal fortgesetzt hat. In Fig. 31, Taf. XVIII, ist ein Längsschnitt des Kommunikationsweges (Cw) wiedergegeben. Wie Fig. 12 demonstriert, ist das Epithel im Seitenkanal zu einer nmfangreichen, soliden Masse (i. S) angebaluft, die, in ständiger Proliferation begriffen, den ihr zu eng gewordenen Raum in der Richtung des geringsten Widerstandes zu durchbrechen droht. In diesem Sinne ist die aussergewöhnliche Erweiterung des Kanallumens aufzufassen. In vier mächtigen Epithelzapfen (Ez) dringt hier das Epithel zur Haut (Iv) vor. Der Druck wirkt auf den Knochen des Seitenkanals (i. S. K) zurüick, und dieser beengt wiederum die Conjunktivalfalte $(C)$, welche sich bereits im Stadium einer Epithelverdickung befindet. So kommt zu dem erwähnten hier schon bestehenden Reizzustande noch der Druck von der Epithelwucherung im infraorbitalen Seitenkanal (i. S) hinzu. Dieser Umstand ist es wohl hauptsächlich, welcher die gitterförmige bindegewebige Durchsetzung (g) der zu einer Epithelverdickung umgewandelten Conjunktivalfalte (C) bewirkt. Die Bälkchen des Gitters schliessen so aneinander, dass sie einen wirksamen Schutz darstellen gegen das Hineinpressen des Seitenkanalknochens (i. S. K) in die Conjunktivalfalte (C) oder gar ins Auge. Die Gefăsse (G) des Coriums sind stark dilatiert, wie überall da, wo dieses auch sonst an einer Integumentverdickung beteiligt ist.

Auf dem natürlichen Wege des Naseneinganges breitet sich die Neubildung auch in der Nasengrube aus. Sie befällt hier vorzugsweise die Nasenfalten. 
In dem auf Fig. 10 abgebildeten Tumor ist auf der rechten Seite die äusserste Nasenfalte (Nf) ergriffen. Eine mächtige Epithellage (w. E), die die normale stellenweise um das 20 fache übertrifft, umgibt das bindegewebige Gerüst der Falte. Während dieses hier überhaupt nicht beteiligt ist, hat es sich auf der' linken Seite stark verdickt (Nf), ohne dass eine entsprechende Epithelverdickung zu bemerken wäre.

Eine ganz erhebliche Ausdehnung erreicht die Integumentverdickung in der linken Nasengrube bei dem schon unter $\mathrm{Nr} .2$ erwähnten Stint. Wie Fig. 31 und 12 demonstrieren, ist hier auch ein Seitenkanal in die Neubildung der Haut mit einbezogen worden. In der Nase (Taf. XVIII, Abb. 28) sind alle drei Nasenfalten ergriffen. Die der Medianebene am nächsten liegende $\left(\mathrm{N}_{\mathrm{f}}\right)$. ragt aus der Nasenöffnung hervor. Sie ist um das Doppelte verlängert und sehr erheblich verdickt. Während die normale Falte glatte Wände besitzt, ist hier namentlich die rechte Wand mit starken Ausstülpungen versehen. Ebenso verhält sich die Nasenfalte auf der ausseren Seite $\left(\mathrm{Nf}_{3}\right)$. Hier ist das Epithel (w. E) in noch starkerer Wucherung begriffen. Am oberen Ende ist es mit dem Epithel des Naseneingangs verwachsen (V). Der Ausweg an dieser Stelle ist darum versperrt. So kommt es, dass hier die Epithelmasse in den kaudalen Nasenblindsack (K. N) hineingepresst wird.

Ein interessantes Phänomen zeigt die mittlere Nasenfalte $\left(\mathrm{Nf}_{2}\right)$. Auch an dieser ist eine Epitbelverdickung unzweifelhaft vorhanden. Wahrend aber die Epithelmasse an den beiden andern Falten fast ausschliesslich aus Stützzellen besteht, kann man hier $z$ wei Zonen deutlich unterscheiden $(x, y)$, von denen sich nur die innere (y) aus Stützzellen aufbaut, während die äussere ( $x$ ) fast vollständig aus Riechepithel besteht. Dasselbe ist gruppenweise zu Knospen angeordnet, die sich stielförmig verjüngen und mit dem bindegewebigen Gerüst in Verbindung stehen. Die Riechzellen nehmen stellenweise die ganze Oberfläche der mittleren Sasenfalte ein und werden nur hier und da von solitären Schleimzellen unterbrochen. Zwischen der bindegewebigen Achse (s. B) der Falte und den Riechzellen liegt die mächtige Schicht von Palisadenzellen (y), welche nach Art der Epithelverdickung wuchern. Die ungewöhnlich zahlreiche Anhäufung von Riechzellen an der Oberfläche der verhältnismässig noch wenig veränderten mittleren 
Nasenfalte entspricht ihrer erhöhten funktionellen Beanspruchung. Die beiden andern Falten sind ja durch die Tumorbildung gänzlich ausser Funktion gesetzt worden.

Die Bedeutung der freien Durchgängigkeit der Nasenöffnung für die Funktionstüchtigkeit des Riechepithels erhellt am besten aus dem in Fig. 30 abgebildeten Fall. Hier hat die Integumentverdickung, die sich auf der Haut ausbreitet, auch die Vasengrube (Na) befallen. Dabei sind die Naseneingänge (V) vollkommen verwachsen. Das histologische Bild zeigt nun das völlige Fehlen von differenziertem Riechepithel. Die Tumorzellen tragen durchaus den Charakter des Stützepithels. Wie eine homogene Vlasse lagert das Epithel an den Wänden. In der Mitte der Nasengrube, wo man sonst die Falten antrifft, ist es zu Detritus (d. E) umgewandelt. Unter dem Druck der Epithelwucherung haben sich offenbar die einzelnen Falten rïckgebildet. Sie sind atrophiert. Nur ein kümmerlicher Rest einer mittleren (Nf.) ist vorhanden, der bei längerer Lebensdauer des Fisches wohl auch geschwunden wäre.

Diese Beobachtungen an den Integumentverdickungen in der Nase lassen es jetzt auch verständlich erscheinen, wieso selbst in den frühesten Stadien der Epithelwucherung in den Seitenkanälen kein Sinnesepithel mebr anzutreffen ist. Offenbar kann hier sehr bald durch einen soliden Epithelverschluss in einem Seitenkanalabschnitt, der zwischen den Abgangsstellen zweier Kommunikationswege liegt, die Strömung unterbunden werden. Infolge des Funktionsunvermögens oder unter dem herrschenden Druck, dem gegenüber das differenzierte Sinnesepithel viel empfindlicher sein dürfte als das Stützepithel, bildet sich allem Anschein nach jenes zurück und geht vollständig verloren.

Über das weitere Schicksal einer derartig umgewandelten Nasengrube kann ich wegen Mangel an geeigneten Präparaten nichts berichten. Eine eintretende Regeneration des Sinnesepithels aus dem normalen Deckepithel der Haut nach vollständiger Abstossung der zu Detritus umgewandelten Epithelmasse erscheint mir nicht ausgeschlossen, nachdem neuerdings Beigel-Klaften (1913) bei jungen Cypriniden dieses experimentell nachgewiesen hat.

Einen interessanten Befund in einer Nasenfalte, den Taf. XVI, Abb. 25 demonstriert, möchte ich noch erwähnen. Hier 
ist der obere Rand einer Falte in eine Cyste umgewandelt. Die mittlere Nasenfalte gabelt sich in eine laterale und eine mediale Sekundärfalte. Wie auf Fig. 25 deutlich zu erkennen ist, ist in das bindegewebige Substrat der lateralen Sekundarfalte eine mächtige Cyste eingelagert. Dieselbe besteht aus einer sehr dünnen Wand, die sich aus offenbar in Degeneration befindlichen Zellen (d.E) aufbaut, und schliesst ein weites, prall mit Flüssigkeit gefülltes Lumen ein. Auch in der Mitte befindet sich etwas Zelldetritus (d.E). Dieser ähnelt in seinem fürberischen Verhalten den zerfallenden Zellen in den flossenständigen cystenartigen Neubildungen. Da ich - wie bereits erwahnt - anderwarts am Kopf zwei cystenförmige Neubildungen angetroffen habe, die den Flossencysten histologisch genau entsprechen, so dürfte das volliegende Gebilde wohl von einer typischen Cyste abzuleiten sein.

Zum Schluss möchte ich kurz von der Kiemenepithelverdickung berichten, die ich allerdings - wie eingangs erwähnt nur bei ein em Stinte angetroffen habe. Die aussere Form und der histologische Bau entsprechen den schon in der historischen Einleitung ausführlich erwähnten Befunden Plehns und $\mathrm{Ma} z \mathrm{a}$ rellis bei andern Salmoniden. Das unter normalen Verhältnissen nur einschichtige respiratorische Epithel ist in dem auf Taf. XVI, Fig. 15 abgebildeten Falle immens gewuchert (w.E), derart, dass die Kiemenblüttchen grösstenteils in homogener Weise verwachsen sind (Ki). Makroskopisch bildet das Kiemenepithel an dieser Stelle eine solide Masse. Das Bindegewebe nimmt keinen Anteil an der histologischen Veränderung. Es handelt sich hier daher nur um eine reine Epithelhyperplasie. Das Epithel zeigt stellenweise eine derartige Schichtung, wie ich sie bei den Neubildungen beschrieben habe, in denen Einschlüsse zu finden waren. Im Gegensatz zu den Befunden von Plehn (1909), die entsprechende Einschlüsse in den Kiemenepithelverdickungen des Bachsaiblings fand, sind jedoch in den gewucherten Kiemenepithelzellen des Stintes keinerlei Zelleinschlüsse anzutreffen. Es ist allerdings wahrscheinlich, dass hier noch ein relativ frühes Stadium vorliegt, so dass sich bei fortschreitender Degeneration immerhin noch jene Einschlüsse bilden könnten.

\section{Zusammenfassung.}

Die milchglasfarbenen Stintneubildungen des Kopfes zeichnen sich durch ihre schon frühzeitig auftretende prominente Gestalt 
aus (Taf. XVI, Abb.4-6). Wie an den Flossen kann man auch hier zwei Formen unterscheiden. Die einen weisen einen primitiven Bau auf und stellen reine Epithel- oder Integumentverdickungen dar, die andern sind komplizierter zusammengesetzt - organoid - und repräsentieren papillomatöse Gebilde. Letztere sind die hăufigsten aller Stintneubildungen.

\section{A. Organoide Formen.}

Den weitaus grössten Anteil an organoiden Formen liefern die lippenständigen Neubildungen. Diese entspringen in der Regel vor der ausseren Epithelseite eines Wulstes, welcher normalerweise die freien Mundrănder lippenartig verlängert.

In jungem Stadium stellen die organoiden Neubildungen hirsekorngrosse Tumoren dar, die mit ziemlich breiter Basis der Interlage aufsitzen (Taf. XVII, Abb. 17, 18 und 20). Sie bauen sich aus Epithel und Bindegewebe auf. Das Corium entsendet in die Epithelmasse fächerbildende Lamellen, in die sich die Epithelzellen nestartig einordnen. Diese zeigen gelegentlich (rustabildungen, deren Entstehung durch Druckwirkungen beim Kieferschluss erklärt werden kann (Taf. XVIII, Abb. 19). Einzelne Neubildungen besitzen eine blumenkohlartig zerklüftete Obertläche (Taf. XVII, Abb. 22). Manchmal erleidet der Tumor eine Quetschung, welche durch den Biss der Zähne verursacht wird. Es entstehen dann auf der Obertläche des Tumors keilförmige Einkerbungen. Das histologische Bild erinnert hier häufig an das der Karzinome (Taf. XVII, Abb. 20). Andere Neubildungen fallen durch die unregelmässige Verteilung von Schleimzellen auf. Die in der Mundhöhle befindlichen Tumorteile zeigen in der Regel eine Lockerung ihres Zellgefüges.

Mit zunehmendem Alter entwickeln sich die histologischen Veränderungen zu Körperanhängen von abenteuerlicher Gestalt (Taf. XVI, Abb. 1 und 3; Abb. 7 und 8). Man findet dann meistens mehrere von ihnen $z u$ einer Gruppe vereinigt (Iaf. XVII, Abb. 10). Neben der Ausbildung eines oft mächtigen Stieles interessieren hier vor allem die nach Art eines autonom wachsenden Gebildes - eines Organs - sich ausbreitenden und formenden Bindegewebslamellen (Taf. XVII, Abb. 21 und 10). Kieferdeformitäten von beträchtlichem Umfange sind häufig die Folge hiervon (Taf. XVII, Abb. 20, 21 und 10). In diesem vor- 
gerückten Stadium begegnet man auch merkwürdigen Zelleinschlüssen des Epithels, welche wohl hyalinen Degenerationsvorgaingen ihre Entstehung verdanken.

Bemerkenswert ist ein Fall, wo zwei Neubildungen des Ober- und Unterkiefers miteinander verwachsen sind (Taf. XVII, Abb. 24).

B. Primitive Formen.

Die primitiven Formen der kopfstandigen Yeubildungen unterscheiden sich von den organoiden durch ibre flachere Ausbreitung und ihre einfache histologische Organisation, die meistens in einer Epithel- oder Integumentverdickung besteht. Mitunter können sie jedoch in eine organoide übergehen (Taf. XVII, Abb. 10). Dort, wo ständige Reize statttinden, kann es zu Einwucherungen des Epithels in das Corium kommen (Taf. XVIII, Abb. 27). Verbreitet sind Degenerationsvorgänge in "Physalid en"-Form (Taf. XVI, Abb. 23). Gelegentlich bildet sich im Epithel eine gitterartige Verästelung des Bindegewebes, die als Reaktion auf Druck aufzufassen ist (Taf. XVIII, Abb. 12).

Nach Art der Epithelwucherungen erliranken die Seitenkanäle, nach Art der Integumentverdickungen die Nasengruben. In beiden Fällen sind stets Kommunikationen mit Neubildnngen anf der Haut ersichtlich (Taf. XVIII, Abb. 30 und 31).

In den Seitenkanälen kommt es zu einer solidenl Ausfüllung des Lumens durch einen Epithelzylinder (Tat. XYII, Abb. 10; Taf. XlIII, Abb. 31 und 30), welcher den Kanal auseinanderzudrängen versucht (Taf. XVIII, Abb. 12). Das Sinnesepithel geht hierbei früh zugrunde.

In der Nase werden nur die Falten ergriften, nicht die Blindsäcke (Taf. XVIII, Abb. 28). Das Bindegewebe der Falten wuchert lebhaft, so dass diese bedeutend vergrössert werden. Das Riechepithel bleibt auf der Obertläche des zu einer mächtigen Yasse angehäuften Epithels stellenweise oft funktionstüchtig. Wenn die Nasenöffnungen verwachsen, tritt eine vollkommene Degeneration des Epithels ein und eine totale Atrophie der Falten (Taf.XVIII, Abb. 30). Auffallend ist die gelegentliche Lmwandlung einer Nasenfalte zu einer echten Cyste (Taf. XYI, Abb. 25).

Die Kiemenepithelverdickungen stellen reine Epithelwucherungen ohne Beteiligung des Bindegewebes dar (Taf. XVI, Abb. 15). 


\section{Schluss.}

Wie die vorliegenden Untersuchungen zeigen, stellen die histologischen Integument- und Schleimhautveränderungen der Stinte Gebilde dar, die nach ihrer Bauart und ihren Wachstumserscheinungen als Neubildungen des Epithels - meistens mit gleichzeitiger Bindegewebsbeteiligung - anzusehen sind. Unter den vielen Unterschieden, die die Neubildungen aufweisen, ist besonders bemerkenswert das Auftreten zweier Organisationsformen, einer relativ selteneren primitiven und einer häufigeren organoiden, die in der Regel einem jungen und einem älteren Stadium der Neubildung entsprechen. Die wichtigsten Unterschiede, die im histologischen Bau zu finden sind, ergeben sich aber aus der Lokalisation der Neubildungen, welche sich an verschiedenen Körpergegenden verschieden entwickeln. Hierbei nimmt der Entwicklungsgang der Hossenständigen Neubildung - von einer reinen Epithelwucherung zu einem Cystengebilde unter allen überhaupt bekannten Neubildungsformen des Integuments der Wirbeltiere eine isolierte Stellung ein.

In histologischer Hinsicht lassen auch die kopfstandigen papillomatösen - Formen der Stintneubildungen gewisse Eigentümlichkeiten erkennen, die ihnen eine besondere Bedeutung verleihen. Die schon im Cystenstadium angebahnte orga nartige Anordnung des Epithels und des Bindegewebes ist hier noch viel deutlicher ausgeprägt. Dieses Verhalten der genannten Gewebe kommt bei den papillomatösen Formen besonders durch eine Anordnung zum Vorschein, welche der Neubildung die rationellste Ernahrung sichert und sie bei eingetretenen Druckwirkungen bestmöglichst entlastet. Bei allseitig erfolgendem Druck wie es z. B. bei fest eingekeilten Epithelzelihaufen der Fall ist reagiert die Zelle durch eine Crustabildung. Sie ist nur bei jugendlichen Formen zu beobachten und darf als ein Ausdruck gesteigerter Funktion angesehen werden. Auf älteren Stadien treten hăufig Einschlüsse von einem eigentümlichen Verhalten auf, die einen Vorgang regressiver Metamorphose darstellen dürften.

Von den primitiven Formen verdienen die in der Nase, Seitenkanal, gelegentlich auch auf der Kieme auftretenden Epithelund Integumentverdickungen eine besondere Beachtung, da sie mit fortschreitender Entwicklung die Funktion der genannten Organe vollkommen lahm legen können. 
Ein Vergleich all der vorliegenden Befunde mit solchen bei andern bekannten Fischgeschwülsten scheitert zum Teil am Mangel homologer Erscheinungen bei letzteren. Auf den einzig dastehenden Entwicklungsgang der Hossenständigen Jeubildung zur Cyste babe ich schon bingewiesen. Ebenso ist das Auftreten von Epithel- and Integumentverdickungen in der Nase und im Seitenkanal, sowie ihr eigenartiges Verhalten daselbst bei andern Fischarten noch unbekannt. Schliesslich habe ich auch die Crustabildung der Epithelzellen und die nach "rationellen" Prinzipien ertolgende Verteilung und Anordnung des Epithels und Bindegewebes in Neubildungen in der mir zugiinglichen Literatur noch nicht beschrieben gefunden.

Immerhin bleibt noch eine Menge von Vergleichsmomenten übrig, voll denen nur die wichtigsten gestreift und kritisch beleuchtet werden sollen. So zeigt ein Vergleich der gelegentlich der Tntersuchung der Karpfenpocken von Plehn $(1906,1909)$ mitgeteilten Befunde mit den vorliegenden Ergebnissen, dass die histologischen Veränderungen des Integuments und der Schleimhaut beim Stint den Karpfenpocken sehr nahe stehen. Hier wie dort ist die Nultiplizität im Auftreten charakteristisch für die Neubildungen und ihre ausschliessliche Entsteliung aus Haut- und Mundschleimbaut nachweisbar. Auch die höckerige Gestalt der Neubildungen sowie ihre eigenartige derbe Konsistenz und ibr milchglasähnlicher Schimmer ist bei beiden Fischarten zu beobachten. Mehr aber noch wie diese üusseren Merkmale spricht die Art der Verbreitung der Karpfenpocken und der Stintneubildungen für eine einheitliche Krankheitserscheinung. Hier wie dort werden nämlich sehr $z$ ablreiche Exemplare betroffen und fast stets nur die Insassen eines lokal begrenzten Wassergebietes. Dieses Verhalten tritt in einer so auffalligen Weise in Erscheinung, dass der Verdacht einer infektiösen Entstehungsursache sehr nahe liegt. All den genannten Faktoren, die für eine gemeinsame Krankheitserscheinung sprechen, können gewisse - ausschliesslich bei den Stintneubildungen beobachtete Befunde keinen Abbruch tun. Ein Teil der Befunde - wie Crustabildung und Zelleinschlüsse - sind auch bei den Stintneubildungen nicht durchgängig anzutreffen, sondern nur unter besonderen Bedingungen. Auf der anderen Seite hat auch Löwenthal (1907) bei den Karpfenpocken gewisse Plasma- 
einschlüsse gefunden, von denen Plehn (1909) gelegentlich einer Nachuntersuchung festgestellt hat, dass sie oft ganz fehlen können, und die nach meinen Beobachtungen bei den Stintne ubildungen überhaupt nicht vorkommen. Diesen prinzipiellen Unterschieden gegenüber darf dem Umstande nur eine relative Bedeutung beigemessen werden, dass die Cyprinidenpocken selten einen organoiden Charakter annehmen, die histologischen Veränderungen des Stints aber in der Regel.

Trotz der auffälligen Verwandtschatt beider Krankheitsformen habe ich mich von ihr hinsichtlich der Bezeichnung in Anbetracht dessen, dass die Stintneubildungen bisher noch nicht anderweitig untersucht wurden - fast gar nicht leiten lassen. Ich habe daher die fraglichen Integument- und Schleimhautgebilde mit der indifferenten Bezeichnung „histologische Veränderungen" oder "Stintneubildungen" belegt. Lediglich die Hossenstandige Epithelwucherung - das Jugèndstadium der Cyste - benenne ich wegen der ausgesprochenen Ïbnlichkeit mit der typischen Epithelwucherung der Karpfenpocke als „pockenartige Epithelwucherung".

Was die Gut- oder Bösartigkeit anbetrifft, so haben wir es beim Stint prinzipiell mit gutartigen Neubildungen zu tun. Allerdings ist in einigen Fällen ein aktives Eindringen von Epithelzapfen in die Tiefe zu beobachten. Doch geschieht dieses nie mit verwischten Grenzübergängen wie bei Warmblüterkarzinomen, welche die Umgebung rücksichtslos zerstören. Man kann darum bei den in Betracht kommenden Neubildungen beim Stint nur von einer andeutungsweise vorhandenen Malignität sprechen. Auch Plehn (1906) berichtet schon von ähnlichen Beobachtungen und kommt dabei $\mathrm{zu}$ folgendem Schluss: "Wir haben also bei Fischen so wenig wie bei höheren Tieren die Möglichkeit, eine scharte Grenze zwischen gutartigen und bösartigen Tumoren zu ziehen."

Als Lösungsversuch für die Frage der Entstehung maligner Tumoren hat Boveri (1914) u. a. die Hypothese aufgestellt, dass neben abnormen Mitosen „ein gewisser abnormer Chromatinbestand, gleichgültig wie er entsteht", das Wesentliche ist. Dahin gerichtete Untersuchungen bei den Stintneubildungen, um auf diese Weise ibren gut- oder bösartigen Charakter zu entscheiden, ergeben nie einen von der Norm abweichenden Chromatinbestand. 
Auch die Mitosen verlaufen stets regetmässig dort, wo sie $z u$ beobachten sind.

Was die Vatur der mutmaßlichen Uisache für die Entstehung der Neubildungen anbetriftt, so steht es zunächst fest, dass ein e gemeinsame für alle Formen vorhanden sein muss. Natürlich ist es aber nicht ausgeschlossen, dass in manchen Fällen ein Komplex von Faktoren an der Ausbildung der einzelnen Formen mitbeteiligt ist. Anhaltspunkte für eine parasitare Ursache babe ich, wie schon gelegentlich erwähnt, nicht finden können. Immerhin ist eine derartige Annahme sehr verlockend in Anbetracht der endemischen Verbreitung der Stintneubildungen. Aber die negativ verlaufenden Untersuchungen über die Ursache der schon länger als ein Jahrzebnt bekannten Karpfenpocken lassen einen dahingehenden Versuch bei den Stintneubildungen nicht gerade als sehr aussichtsreich erscheinen. Bei den Stintneubildungen lüsst sich jedenfalls das eine mit Bestimmtheit sagen, dass eine von a ussen her kommende Einwirkung ein ursächliches, zum mindesten aber auslösendes Moment bilden muss. Dafür spricht die auffüllige Verbreitung der histologischen Veränderungen an der Körperobertläche, besonders aber an Gegenden, die bei der Vorwärtsbewegung des Fisches gegenüber iusseren Schädigungen stark exponiert sind. Von diesem Gesiclitspunkt aus ist auch die Verschiedenwertigkeit zwischen Haut und Schleimhaut bezüglich des Befallenwerdens wohl zu verstehen. Denn die Haut ist äusseren Reizen in viel grösserem Maße ausgesetzt als die Schleimbaut in der Mundhöhle, Nasengrube und den Seitenkanälen.

Von Wichtigkeit ist es hierbei auf alle Fälle, zu entscheiden, ob die histologischen Verănderungen von vornherein als autonome Gebilde entstehen oder als Ausdruck eines entzündlichen Prozesses aufzufassen sind, welcher später nur einen selbständigen Charakter annimmt. Wenn auch gewisse Befunde in der Integumentverdickung - wie z. B. kleinzellige Infiltrationen und dilatrierte Gefässe - für einen entzündlichen Vorgang sprechen, so kann dieser aber auch andererseits als eine Folgeerscheinung angesehen werden, zumal man auch bei organoiden Formen ein derartiges Verhalten antreffen kann.

So wenig Sicheres sich nun vorläufig über die Entstehungsursache der histologischen Veränderungen sagen lässt, so wenig 
lässt sich ihre endemische Verbreitung erklären. Auf der einen Seite legt das gehäufte Auftreten eine Ursache nahe, die durch den Ort der Ausbreitung bedingt sein muss. Auf der andern Seite muss man an Rassendisposition denken. So hält z. B. Fiebiger (1908) mit Rücksicht auf die Tatsache, dass oft Fische nur eines Teiches von Neubildungen befallen werden, es für ,sehr naheliegend, in der gemeinsamen Abstammung das ursächliche Moment zu erblicken, d. h. für die Entwicklung der Neoplasmen eine gleiche ererbte Anlage anzunehmen". Eine Bekräftigung oder Ablehnung dieser Annahme im Hinblick auf die Stintneubildungen kann jedoch erst erfolgen, wenn die Frage ihrer Ansteckungsmöglichkeit entschieden ist. Ferner muss man zuvor feststellen, ob auch an andern Ostseestellen die bis jetzt mir nur von Rügen her bekannten histologischen Veranderungen angetroffen werden. Probeentnahmen aus den reich beschickten Berliner Markthallen ergaben stets negative Resultate.

\section{Literaturverzeichnis.}

1. Bashford: Über den Krebs des Menschen und der Tiere. Berliner klinische Wochenschrift, 1909.

2. Bashford-Murray: Scientific Reports on the Investigations of the Cancer Research Fund, 1904, Nr. 1.

3. Dieselben: Scientific Reports Nr. 2.

4. Beige $\mathrm{l}-\mathrm{Klaf}$ te $\mathrm{n}$ : Regeneration des Geruchsorgans bei den Cypriniden Extrait du Bulletin de l'Académie des Sciences de Cracovie, Krakau 1913

5. Boveri: Zur Frage der Entstehung maligner Tumoren. Jena 1914.

6. Bugnion: Deutsche Zeitschrift für Tiermedizin und vergleichende Pathologie, 1875, I. Bd.

7. Dauwe und Pennemann: Contribution à l'etude da Cancer chez les Poissons. Annales de la Soc. de Médec. de Gand.

8. Enzyklopädie der mikroskopischen Technik, 1903.

9. Fibiger: Über eine durch Nematoden (spiroptera sp. n.) hervorgerufene papillomatöse und karzinomatöse Geschwulstbildung im Magen der Ratte. Berl. klin. Wochenschrift, 1913.

10. Fiebiger: Über Hautgeschwülste bei Fischen nebst Bemerkungen über die Pockenkrankheit der Karpfen. Zeitschrift für Krebsforschung, 1909.

11. Derselbe: Ein Rhabdomyom bei einem Kabeljau. Loc. cit. 1909.

12. Derselbe: Ein Osteochondrom bei einem Karpfen. Loc. cit. 1909.

13. Gawrilenko: Die Entwicklung des Geruchsorgans bei Salmo salar. Anat. Anz., Bd: 36, 1910. 
14. Hart: Über die primäre Multiplizität bösartiger Geschwülste usw. Zeitschr. f. Krebsforschung, 1907.

10. Heiden hain: Plasma und Zelle. Jena 1911.

16. Ho fer: Handbuch der Fischlrankheiten. 1906.

17. Keysselitz, G.: Über ein Epithelioma der Barben. Archiv für Protistenkunde, 1908.

18. Kolmer, W.: Zur Kenntnis der Riechepithelien. Anat. Anz., Bd. 30, 1907.

19. Derselbe: Über Strukturen im Epithel der Sinnesorgane. Anat. Anz., Bd. $36,1910$.

20. L e e and Ma yer: Grundriss der mikroskopischen Technik, 1907.

21. L 0 eb, L.: Über einige Probleme der experimentellen Tumorforschung. Zeitschr. f. Krebsforschung, 1907.

22. Löwenthal: Einschlussartige Zell- und Kernveränderungen in der Karpfenpocke. Zeitschr. f. Krebsforschung, 1907.

23. M urray: The Zoological Distribution of Cancer. Third Scient. Report. Cancer Research Fund, 1908.

24. Peter, K.: Die Entwicklung des Geruchsorgans usw. in dem Handbuch der vergl. und exper. Entwicklungslehre der Wirbeitiere von 0 . Hertwig, 1902.

25. Derselbe: Entwicklung des Geruchsorgans. Ergebn. d. Anat. u. Entwicklungsgeschichte, $\mathrm{Bd} .20$.

26. Pick: Der Schilddrüsenkrebs der Salmoniden. Vortrag, 1905 gehalten in der Berliner medizinischen Gesellschaft.

27. Pick und Poll: Tumorbildungen aus der Tierpathologie. Berliner klin. Wochenschrift, 1903.

28. Plehn, M.: Über Geschwülste bei Kaltblütern. Zeitschrift für Krebsforschung, IV, 1906.

29. Dieselbe : Über einige bei Fischen beobachtete Geschwülste und geschwulstartige Bildungen. Berichte aus der Kgl. Bayer. biol. Versuchsstation in München, 1909, Stuttgart.

30. Dieselbe: Über Geschwülste bei niederen Wirbeltieren. Deuxième conférence internationale pour l'étude du cancer, Paris 1910.

31. Dieselbe: Über Geschwülste bei Kaltblütern. Vortrag, gehalten am 4. März 1912 in der k. k. Gesellschaft zur Erforschung und Bekämpfung der Krebskrankheit in Wien. Wiener klin. Wochenschrift 1912.

32. von Prowa zeck: Chlamydozoa. Archiv für Protistenkunde, 1907.

33. Schleip: Die Entwicklung der Kopfknochen bei dem Lachs und der Forelle. Inaug.-Diss., Freiburg i. Breisgau 1913.

34. Schröders: Geschwülste bei Fischen. Dissertation Petersburg 1907.

35. Sticker: Über den Krebs der Tiere. Frankfurt a. M. 1902.

36. Zil z: Symmetrische harte Papillome des Unterkiefers. Ergebn. d. gesamt. Zahnheilk. Wiesbaden 1914. 


\section{Erklärung der Abbildungen 1-31 auf den Tafeln XVI-VXIII.}

Fig. 1. Mächtige Integumentneubildung am Kopf eines Stints, ausgehend von den freien Mundrändern (linke Seite). Phot. n. Zenkerkonserv. Nat. Gr.

Fig. 2. Pockenartige Epithelwucherung an der linken Brustflosse eines Stints. Vergr. 3:2. Phot. n. Formolkons.

Fig. 3. Integumentneubildung 1 von oben gesehen. Nat. Gr.

Fig. 4. Weizenkorngrosse Neubildung am Oberlippenwulst eines Stints. Phot. n. Formolkons. Nat. Gr.

Fig. ら. Multiple Neubildungen an den Mundrändern eines Stints. Auf der linken Brustflosse zu einer Gruppe konfluierte pockenartige Epithelwucherungen. Phot. n. Formolkons. Nat. Gr.

Fig. 6. Mächtige Neubildung, ausgehend vom Oberlippenwulst eines jungen Stints. Phot. n. Formolkons. Nat. Gr.

Fig. 7. Taubeneigrosse Integumentneubildung an einem Stintkopf (obere Ansicht). Phot. n. Formolkons. Nat. Gr. (Vgl. Abb. 21.)

Fig. 8. Dieselbe (untere Ansicht). Nat. Gr.

Fig. 9. Teilstück der mundrandständigen Neubildung des Unterkiefers von 7 (Formol). Häm. Bühm.-Eosin. Gez. Vergr. $103 \mathrm{mal}$.

Fig. 10. Transversalschnitt durch einen Stintlropf mit riesigen Einzeltumoren. Infraorbitale Seitenkanäle (i. S) und Nasenschleimbaut (Nf) sind mit einbezogen. Zenkerkons. Heidenhain-ran Gieson. Gez. Vergr. $10 \mathrm{mal}$.

Fig. 11. Cystenförmige Integumentneubildungen an den Brustflossen eines Stints. Rechts eine isoliert. Links drei zu einer Gruppe vereinigt. (Vorgeschrittenes Stadium der flossenständigen Neubildung). Phot. n. Formolkons. Nat. Gr.

Fig. 12. Querschnitt durch die Epithelwucherung eines Seitenkanals (i. S.). Das ebenfalls ergriffene Epithel der Conjunktivalfalte (C) ist vom Bindegewebe gitterartig (g) durchsetzt. Zenkerkons. HämalaunEosin. Gez. Vergr. 32 mal.

Fig. 13. Querschnitt durch eine flossenständige pockenartige Epithelwucherung (w. E). Formolkons. Häm. Böhm.-Eosin. Phot. Vergr. 34 mal.

Fig. 14. Querschnitt durch eine cystenförmige Integumentneubildung an einer Stintflosse mit solider Epithelmasse (w. E) im Innern. Bindegewebige Kapsel (K) teilweise zur normalen Cutis differenziert. Pikrins.-Subl.-Eisessig-Kons. Heidenhain-van Gieson. Phot. Vergr. $54 \mathrm{mal}$.

Fig. 15. Teil eines Längsschnittes durch die Kiemenblättchen (Ki) eines Stints, welche durch eine Epithelwucherung (w. E) homogen verschmolzen sind. Formolkons. Heidenhain-van Gieson. Phot. Vergr. 25 mal.

Fig. 16. Querschnitt durch eine cystenförmige Integumentneubildung an einer Stintflosse. Im Innern Degeneration des Epithels (d. E.) und baumförmige Verästelung des Bindegewebes (Q1.). (Äusseres Epithel 
[E] künstlich abgehoben.) Zenkerknns. Heidenhain-van Gieson. Phot. Vergr. 34 mal. (Vgl. Abb. 29.)

Fig. 17. Längsschnitt durch eine kurzgestielte, weizenkorngrosse Integumentneubildung, ausgehend vom Unterlippenwulst eines Stints. Unterkiefer (D) liegt infolge Verletzung frei zu Tage. Zenkerkons. Heidenhain. Phot. Vergr. 33 mal.

Fig. 18. Längsschnitt durch eine kurzgestielte, weizenkorngrosse Integumentneubildung, ausgehend vom Oberlippenwulst eines Stints. Zenkerkons. Heidenhain-Lichtgrün. Phot. Vergr. 19 mal.

Fig. 19. Ausschnitt aus 18. Übergang des Hautepithels (E) in das der Neubildung (s. E). Phot. Vergr. 170 mal:

Fig. 20. Längsschnitt durch eine dem Rostrum eines Stintkopfes breitbasig aufsitzende Neubildung. Epithelzapfen (Ez) dringen bis zum Rostrum (R) vor. (Rostralknorpel künstlich gefaltet.) Zenkerkons. Heidenhain-Lichtgrün. Phot. Vergr. $11 \mathrm{mal}$.

Fig. 21. Längsschnitt durch den in Abb. 7 und 8 abgrebildeten stintkupt mit zwei gegenüberstehenden mundrandständigen Integumentneubildungen. Die untere ist langgestielt (St). Formolkons. Boraxkarmin-Indigokarmin. Gez. Vergr. $10 \mathrm{mal}$.

Fig. 22. Tü̈ngsschnitt durch eine blumenliohlartig vom Oberlippenwulst ausgehende Neubildung. Zenkerkons. Hämalaun-van Gieson. Gez. Vergr. 20 mal.

Fig. 23. Physalidenartige Degeneration (d. E.) in der Integumentverdickung eines Stints. Zenkerkons. Häm. Böhm.-Eosin. Gez. Vergr. 109 mal.

Figr. 24. Teil eines Längsschnittes durch einen Stintliopf. Längsschnitt durch zwei miteinander verwachsene Integumentneubildungen, ausgehend von den freien Mundrändern eines Stints. Flemmingkons. Heidenhain. Phot. Vergr. 13,5 mal. (Der untere Teil des Unterkiefers $[D]$ ist horizontal abgeschnitten.)

Fig. 25. Cystenartige Erweiterung in der mittleren Nasenfalte. Zenkerkons. Hämalaun-van Gieson. Phot. Vergr. 30 mal.

Fig. 26. Längsschnitt durch einen in die Tiefe wuchernden Epithelzapfen $(\mathrm{Ez})$ in einer Integumentverdickung (s. B-w. E.) am hinteren Maxillarende eines Stintkopfes. Zenkerkons. Hamalaun-Eosin. Phot. Vergr. $19 \mathrm{mal}$.

Fig. 27. Querschnitt durch eine Integumentverdickung ( $\mathrm{Iv}$ ) an einem Stintkopf. Epithelzapfen (Ez) dringen bis zum infraorbitalen Seitenkanal (i. S.) vor. (Zenker.) Häm. Böhm.-Eosin. Phot. Vergr. $93 \mathrm{mal}$.

Fig. 28. Querschnitt durch die Nasengrube eines Stints. Epithelwucherung der Riechschleimhaut (w. E). Zenkerkons. Hämalaun-Eosin. Phot. Vergr. 25, 5 mal.

Fig. 29. Ausschnitt aus Abb. 16. Epitheldegeneration (d. E) zwischen von der Kapsel losgelösten bindegewebigen Verästelungen (Ql) im Cysteninnern einer Stintflosse. Gez. Vergr. 103 mal.

Fig. 30. Querschnitt durch die Nasengrube (Na) eines Stints. Vom Hautepithel ausgehende bereits in Degeneration befindliche Epithel- 
wucherung der Nase (d. E) und des infraorbitalen Seitenkanals (i. S). Nasenöffnungen verschlossen (V). Nasenfalten (Nf) atrophiert. Zenkerkons. Hämalaun-van Gieson. Gez. Vergr. 15 mal.

Fig. 31. Kommunikationsweg (Cw.) des in Abb. 12 angestellten infraorbitalen Seitenkanals. Integumentrerdickung der Haut (Iv.) greift auf das Epithel des Seitenkanals über. Zenkerkons. Hämalaun-Eosin. Gez. Vergr. $12 \mathrm{mal}$.

\section{Erklärung der Abkürzungen im Text und auf den Tafeln.}
s. B. = straffes Bindegewebe.
C. $=$ Conjunktivalfalte.
Cw. = Kommunikationsweg des Seitenkanals.
D. = Unterkiefer.
d. $=$ distaler Flossenrand.
E. = normales Epithel der Haut.
d. E. = degenerierte Epithelzellen.
i. E. = inneres Epithel des Lippenwulstes.
s. E. = spindelförmige Epithelzellen.
w. $\mathrm{E}=$ Epithelwucherung.
Er. = Erosionsfläche.
Ez. = Epithelzapfen.
F. $=$ Flossenstrahl.
G. $=$ Gefässe.
g. = gitterförmige Verbreitung des Bindegewebes.
Gl. = Gewebslïcke.
H. = Hohlraum.
Iv. = Integumentverdickung.
Ki. = Kiemenblättchen.
K. = bindegew ebige Kapsel.
L. = bindegewebige Lamellen.
Ma. $=$ Maxillare.
M. = Mulde.
Na. $=$ Nasengrube.
Ni. = Nasenfalte.
k. N. = kaudaler Nasenblindsack.
P. = Pigment.
Pa. = Palatinum. 
264 Theodor Breslauer: Zur Kenntnis der Epidermoidalgeschwülste.

Pm. = Prämaxillare.

Ql. = Querlamellen.

R. = Rostralknorpel.

St. $=$ Stiel.

i.S. = infraorbitaler Seitenkanal.

i. S.K. = Knochen des infraorbitalen Seitenkanals.

V. = Verschmelzung zweier Epithelschichten.

$\mathrm{Vb} .=$ Verbindungsstiicke von Querlamellen. 


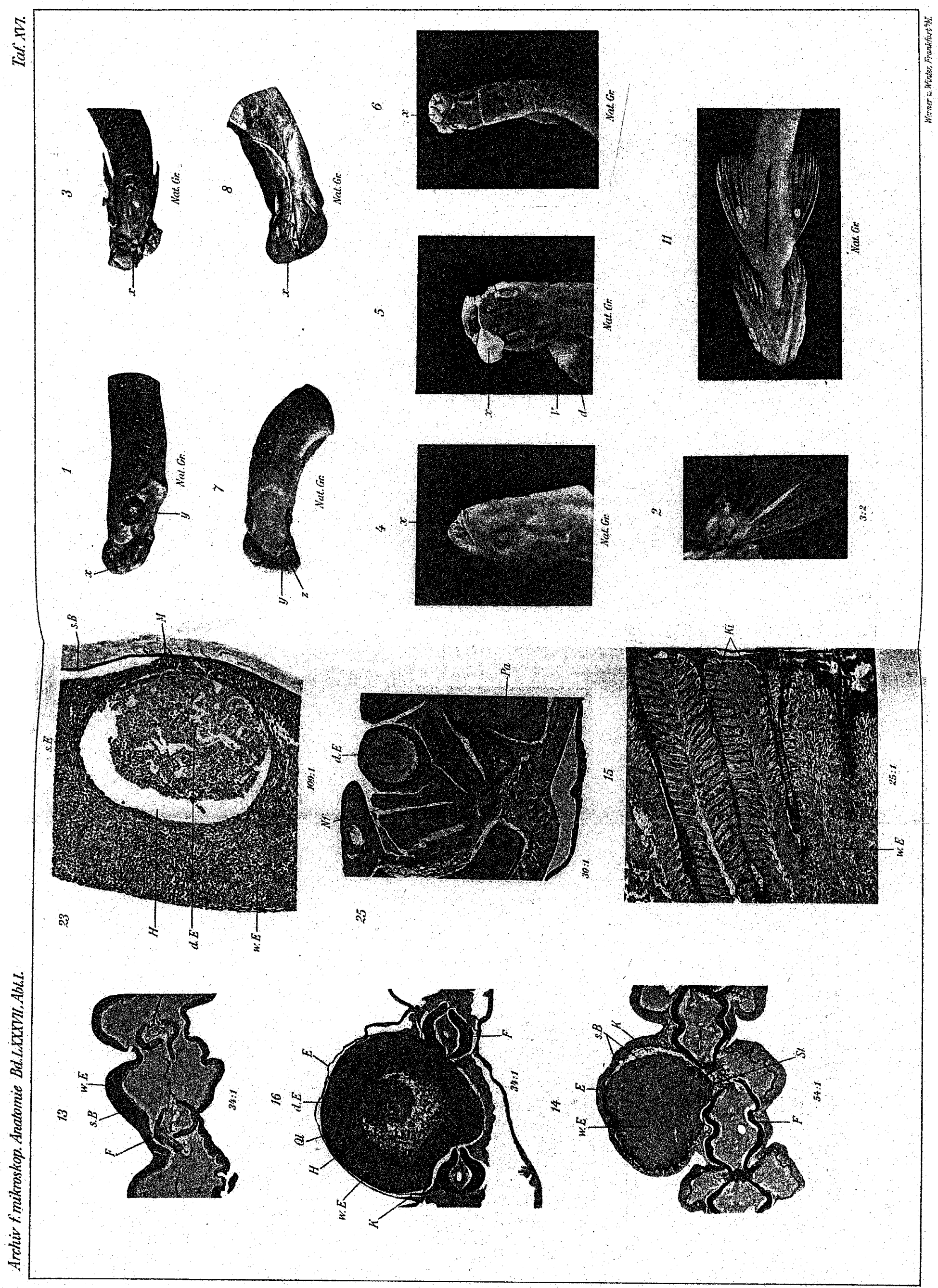




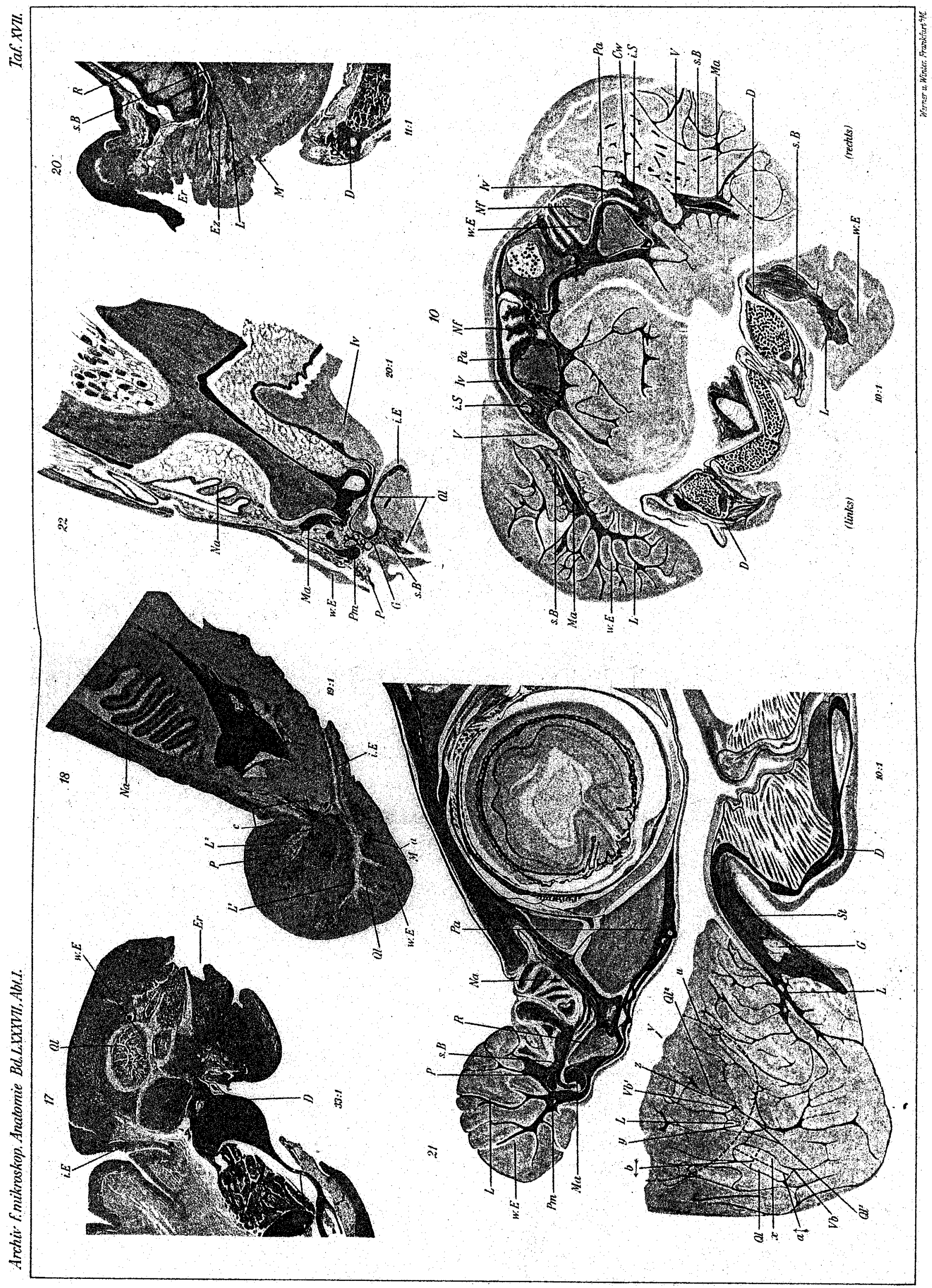




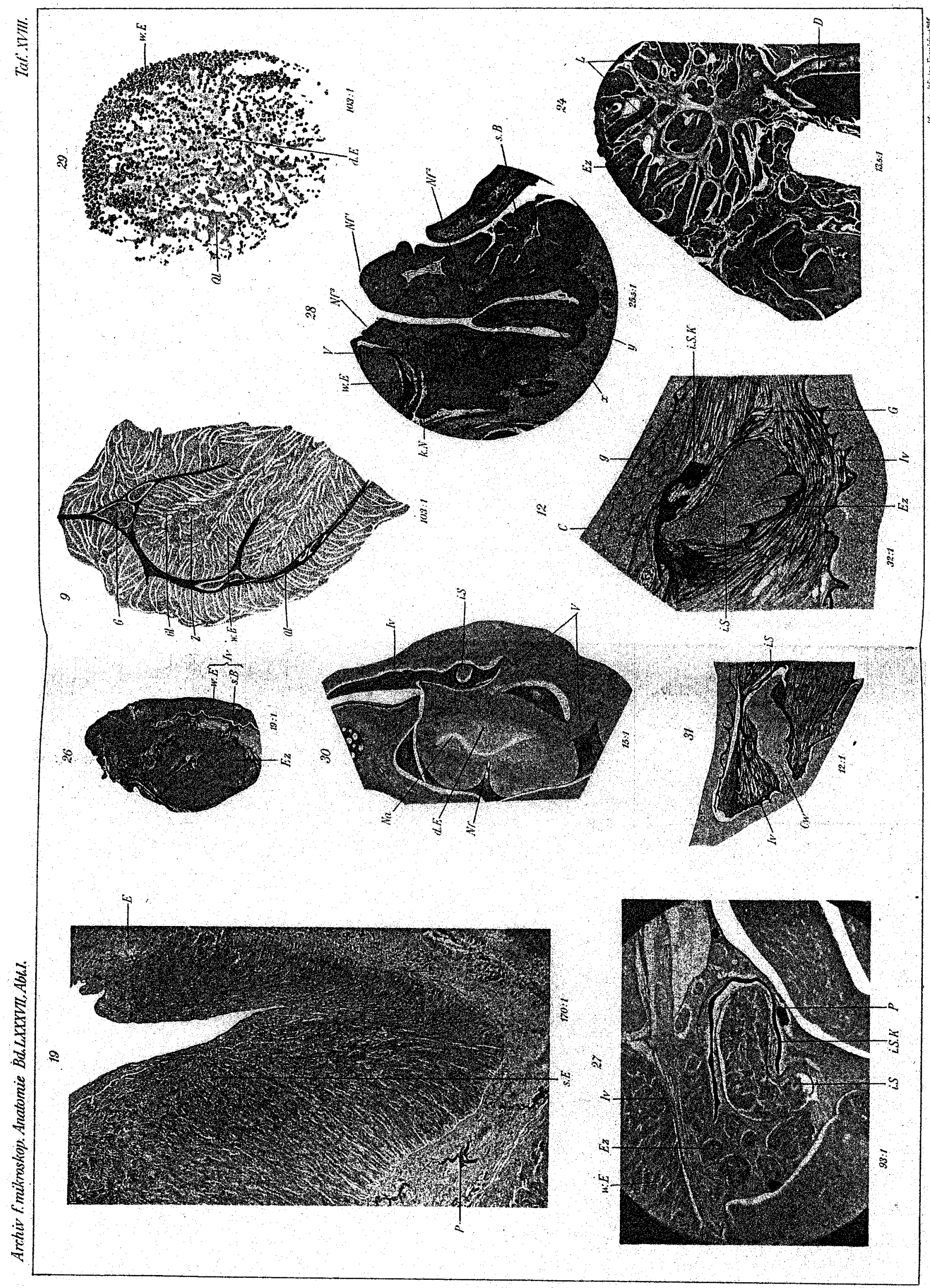

